\title{
Knowledge, Attitude, and Practice of Foot Care among Type 2 Diabetic Patients Attending Diabetic Clinic. Al Ribat Teaching Hospital in Sudanese Patients
}

\author{
Maha Abuelgasim Alamil Mohammed ${ }^{1}$, Nazik Ibrahim Abdel Rahman,"* \\ ${ }^{1}$ Faculty of Medicine, Omdurman Islamic University, Sudan \\ ${ }^{2}$ Faculty of Medicine, Alzaiem Alazhari University, Sudan
}

Copyright $\bigcirc 2018$ by authors, all rights reserved. Authors agree that this article remains permanently open access under the terms of the Creative Commons Attribution License 4.0 International License

\begin{abstract}
Diabetic foot complications are a major challenge for the healthcare system, with enormous economic consequences for the patients, their families, and the society and a leading cause of mortality and morbidity in developing countries. Diabetic foot ulcer (DFU) is the

smoking cessation would be beneficial in preventing diabetic foot complication. Policy and decision makers should initiate interventional foot care education programs throughout the country, with our ultimate goal is to save limbs.
\end{abstract} most costly and devastating complication, which affects $15 \%$ of diabetic patients during their lifetime. Good knowledge, attitude, and practice regarding diabetic foot care will reduce the risk of diabetic foot complications and ultimately amputations. The aim of this study was to assess the knowledge, attitude, and practice of foot care among type 2 diabetic patients and to determine the relationship between proper foot care and diabetic foot lesions. This is an observational, descriptive, cross-sectional, hospitalbased study. It was conducted in the diabetic out-patient clinic at Al-Ribat University Hospital, in Khartoum, Sudan 2016. A total number of 156 type 2 diabetic patients were enrolled in this study; with $75 \%$ of the participants were females and $25 \%$ males. Duration of DM, exercise, smoking adherent to diabetic diet, type of therapy, co-morbidity, foot lesions, and foot care knowledge, attitude, and practice were tested. Having diabetes longer than 10 years were $37.8 \%$, mean age was $53.4 \pm 7.68$ years. There was high prevalence of peripheral neuropathy(PN) symptoms $56.4 \%$ while $42.3 \%$ of the patients had peripheral arterial disease symptoms .17 patients had loss of sensation while only 2 patients had loss of peripheral pulses (dorsalis pedis and posterior artery pulses). Regarding knowledge, attitude, and practice about diabetic foot care, $56.5 \%$ had good foot care knowledge, $70.5 \%$ had bad attitude, and $62.2 \%$ had moderate practice. Based on Chi square test of relationship between proper foot care and diabetic foot ulcer (DFU), there was association between bad knowledge, attitude, and practice about foot care and DFU, P. values: 0,03, 0,000, 0.036 respectively. Advising the diabetics about frequent foot care clinic visits, regular feet examination, proper footwear, exercise program, and

\section{Keywords Diabetes Mellitus, Foot Care}

\section{Introduction}

Diabetic foot disease is one of the most common and distressing complications that affect diabetic patients.It is a major challenge for the healthcare system , leading to enormous economic consequences for diabetic patients ,their families ,and government.[1][2].

Diabetic foot disease accounts for $20 \%$ of all hospitalizations of type 2 diabetes patients in sub-Saharan Africa, and frequently leads to chronic disabilities, loss of income, lower limb amputation and death. [2][3][4][5]. It accounts for more hospital admissions than any other complication of diabetes, and contribute substantially for health care costs.

A proximately $15 \%$ of all diabetics will develop some foot problems during the course of their illness [6]. 15\% of patients with diabetes will have a foot ulcer at some point in their lives [7].More than $50 \%$ of non-traumatic lower limb amputations are performed on patients with diabetes [8].

Foot complications in diabetes include:

- Peripheral neuropathy.

- Peripheral vascular diseases.

- Foot ulcerations.

- Foot infections and osteomyelitis.

- Amputations.

- Charcot's neuroarthropathy. 
- Other foot problems includes: calluses and corns, blisters, bunion, in growing toe nails, hammertoes, and dry and cracked skin.

Foot ulcers and amputations in diabetic patients are mainly due to peripheral neuropathy (PN) and peripheral vascular diseases (PV).It estimated that, at the time of diagnosis of type 2 diabetes, more than $10 \%$ of one or two risk factors for foot disease such as PN or PVD [9].

Several studies have shown that a majority of people with diabetes do not receive guideline-recommended foot care, including regular foot examinations. In study conducted by Basu et al in the United Kingdom,33\% of diabetics did not recall receiving information about foot care[10].In another one conducted at Muhimbili National Hospital diabetic clinic, $87 \%$ of patients reported never inspecting their feet, and $66 \%$ reported they were not interested in further knowledge of diabetic foot care [11].

Diabetes mellitus is a common medical problem in Sudan; $15 \%$ of people with diabetes develop ulcers; and 15\% of ulcers result in amputation [12]. According to some studies, the prevalence of DFU among the population of rural Sudan is $3.9 \%$. It causes a high rate of hospital admissions[13]. Recently, DSF accounted for $10.2 \%$ of all complications reported from private clinics in Khartoum state [13].

Around $85 \%$ of amputations could be avoided by early detection of foot complications, timely intervention, and involvement of adiabatic foot care team, good control, and patient educations [14]. Foot self - care behaviors, including daily inspection of feet, professional treatment, hygiene, and proper shoe gear help minimize the risk of foot complications [15].

McCook - Martinez et al.(1979) found that when patients were properly informed about foot care, disease-associated morbidity, hospitalization, and amputation rates were lower than for those that did not have care information[16].

Lavery et al.[17] noted a reduction in hospitalizations and amputations in their study, which developed a lower extremity disease management program that included lower limb screening and treatment protocols for the at risk foot within a health care facility.

This study will be conducted to assess the awareness of diabetic patients about foot care, and identify the role of proper foot care in decreasing or preventing diabetic foot complications. Furthermore, by doing this study, we can help in undertaking better future policies, and implementing better prevention programs that could improve patient quality of life and decrease patient morbidity and mortality.

\section{Literature Review}

Diabetes mellitus is a group of metabolic diseases resulting from defects in insulin secretion, insulin action, or both .The chronic hyperglycemia of diabetes is associated with long- term damage, dysfunction, and failure of various organs especially the feet, eyes , kidneys , nerves ,blood vessels and heart [18]. It is affecting people worldwide and it is one of the most challenging health problems in the 21 century.

It is one of the four priority non-communicable diseases (NCDs) targeted by the world leaders in the 2011 Political Declaration on the Prevention and Control of NCDs [19].

2012 there In were 1.5 million deaths worldwide directly caused by diabetes. It was the eighth leading cause of death among both sexes and the fifth leading cause of death in women in 2012[20].

The number of people with diabetes worldwide has risen from 108 million in 1980 to 422 millions in 2014[21], and the global prevalence of diabetes has risen from $4.7 \%$ in 1980 to $8.5 \%$ in 2014 [21].

According to the International Diabetes Federation Middle East and North Africa 2015(MENA), there were over 1.4 million adult cases of diabetes in Sudan, with the prevalence $7.7 \%$

\section{Path-physiology}

Several pathogenic processes are involved in the development of diabetes. These range from autoimmune destruction of the beta cells of the pancreas with consequent insulin deficiency to abnormality those results in resistance to insulin action. The basis of the abnormalities in carbohydrate, fat, and protein metabolism in diabetes is deficient action of insulin on target tissues. Deficient action of insulin results from inadequate insulin secretion and/ or diminished tissue responses to insulin at one or more points in the complex pathways of hormone action. Impairment of insulin secretion and defects in insulin action frequently coexist in the same patient, and it is often unclear which abnormality, if either alone, is the primary cause of the hyperglycemia.

Symptoms of markedly hyperglycemia include: polyuria, polydipsia, weight loss, polyphagia, blurring of vision, and impairment of growth, and susceptibility to certain infections.

Long- term complications of diabetes include retinopathy with potential loss of vision; nephropathy leading renal failure; peripheral neuropathy with risk of foot ulcer, amputations, Charcot joints; an autonomic neuropathy causing gastrointestinal, genitourinary, and cardiovascular symptoms and sexual dysfunction.

\section{Diagnosis}

Diagnostic criteria of diabetes mellitus (WHO)

1- Symptoms (polyuria, polydipsia, weight loss, DKA, HHS) Plus Random blood glucose level $\geq 1 \mathrm{mmol} / 1$ $(\geq 200 \mathrm{mg} / \mathrm{dl})$ 
2- $\quad$ Fasting blood glucose level $\geq 7.0 \mathrm{mmol} / 1(\geq 126$ $\mathrm{mg} / \mathrm{dl}$ )

3- Plasma glucose during a 2-hour 75g OGTT $\geq 200$ $\mathrm{mg} / \mathrm{dl}(11.1 \mathrm{mmol} / \mathrm{L})$

4- HbAlc $6.5 \%$

In the absence of hyperglycemic symptoms, an abnormal fasting plasma glucose, OGTT, or HbAlc should be confirmed by repeat testing.

\section{Classifications}

1-Type 1 diabetes (T1DM): his accounts for $5-10 \%$ of all diabetics, it results from a cellular-mediated autoimmune destruction of the beta cells of the pancreas, leading to absolute insulin deficiency. It can rapid progression or slow-latent autoimmune diabetes in adults (LADA). Auto antibodies markers include:

- ICA (islet-cell/cytoplasmic /autoantibody).

- GADA(autoantibody to glutamic acid decarboxylase).

- IAA(insulin autoantibody) .

- IA-2A(autoantibody).

2-Type 2 diabetes (T2DM): his form of diabetes present in about $90-95 \%$ of diabetes. It is usually due to peripheral insulin resistance, impaired insulin secretion, excessive hepatic glucose production, and impaired in cretin effect. Risk factors of Type 2 diabetes include:-Family history of Type 2 diabetes, obesity, sedentary lifestyle, previously identified IFG or IGT, history of gestational diabetes, Dyslipidemias, hypertension, polycystic ovary syndrome or acanthosis nigrigans, and history of vascular disease.

3-Other types: Genetic defects of $\beta$-cell function-, they are referred to as maturity onset diabetes of the young (MODY) usually before the age of 25 years. They are usually autosomal dominant inheritance. The most common form is associated with mutations on chromosome 12 in a hepatic transcription factor referred to as hepatocyte nuclear factor (HNF)-1 $\alpha$. A second form is associated with mutations of glucokinase genes on chromosome $7 \mathrm{p}$ and result in defective glucokinase molecule.

\section{Management of Diabetes Mellitus}

The most effective management of diabetes mellitus includes a multidisciplinary approach, including patient education and support, engaging patients in their care and decision making, lifestyle modifications with diet and exercise, reduced caloric intake for overweight and obese patients, and pharmacologic therapies when necessary to meet individualized glycemic goals, as shown in the table below:

Table 1. American Diabetes Association recommended outpatient glycemic goals for adult with diabetes mellitus

\begin{tabular}{|c|c|c|c|c|}
\hline $\begin{array}{l}\text { State of } \\
\text { health }\end{array}$ & $\begin{array}{c}\text { Characteristics } \\
\text { of Patients }\end{array}$ & $\begin{array}{c}\text { Hemoglobin } \\
\text { A1c }\end{array}$ & $\begin{array}{c}\text { Preprandial } \\
\text { Capillary } \\
\text { Glucosea }\end{array}$ & $\begin{array}{l}\text { State of } \\
\text { Health }\end{array}$ \\
\hline $\begin{array}{l}\text { Complex } \\
\text { health } \\
\text { Issues }\end{array}$ & $\begin{array}{c}\text {-Early in disease Course }- \text { Few co morbidities } \\
\text {-Preconception Patient } \\
\text { preference } \\
\text {-Life expectancy }>10 \text { years } \\
\text { - Significant comorbidities, } \\
\text { including advanced } \\
\text { atherosclerosis or } \\
\text { microvascular complications } \\
\text { Longer duration of diabetes } \\
\text { Frequent hypoglycemia } \\
\text { Hypoglycemia unawareness } \\
\text { Life expectancy }<10 \text { years }\end{array}$ & $\begin{array}{c}<7.0 \% \text { without } \\
\text { Severe } \\
\text { recurrent } \\
\text { hypoglycemia } \\
\\
\\
<8.0 \% \text { without } \\
\text { Severe } \\
\text { recurrent } \\
\text { hypoglycemia }\end{array}$ & $\begin{array}{c}70-130 \\
\mathrm{mg} / \mathrm{dL}(3.9- \\
7.2 \mathrm{mmol} / \mathrm{L})\end{array}$ & $\begin{array}{c}<180 \mathrm{mg} / \mathrm{dL}(10.0 \\
\mathrm{mmol} / \mathrm{L})\end{array}$ \\
\hline \multirow[t]{2}{*}{ Olders adults } & $\begin{array}{c}\text {-Few co-morbidities } \\
\text {-Extended life expectancy } \\
\text {-No impairment of cognition or function }\end{array}$ & $\begin{array}{c}<7.0 \%-7.5 \% \\
\text { Without severe } \\
\text { recurrent } \\
\text { hypoglycemia }\end{array}$ & $90-130 \mathrm{mg} / \mathrm{dl}$ & \\
\hline & $\begin{array}{c}\text {-Poor health } \\
\text {-Chronic } \\
\text { Co-morbidities } \\
\text { with end-stage } \\
\text { disease } \\
\text {-Long-term care placement } \\
\text {-Moderate-to severe impairment in cognition and } \\
\text { function } \\
\text {-Limited life expectancy }\end{array}$ & $\begin{array}{c}<8.5 \% \\
\text { without } \\
\text { severe } \\
\text { recurrent } \\
\text { hypoglycemia }\end{array}$ & $\begin{array}{c}100-180 \\
\mathrm{mg} / \mathrm{dl}\end{array}$ & \\
\hline
\end{tabular}




\section{Non-pharmacologic Therapy}

Non-pharmacologic approaches to diabetes management should be implemented throughout the lifespan of the patient. These approaches can be used alone or as adjunct therapy in type 2 diabetes to improve the success rate of pharmacologic agents. Medical nutrition therapy and exercise can be used in conjunction with insulin therapy for patients with type 1 diabetes.

Medical nutrition therapy is an essential component of any successful management plan for patients with pre-diabetes or diabetes. Modest weight loss $(2.0-8.0 \mathrm{~kg}$ [4.4-17.6 lb] or 7\%) through caloric reduction can benefit some overweight or obese adults with type 2 diabetes. Consistent exercise provides beneficial effects on glucose control, weight, and cardiovascular status. For persons with diabetes in whom no contraindications exist, aerobic exercise should consist of at least 150 minutes/week at a moderate intensity level, 75 minutes/week at a vigorous activity level, or a combination of these two.

Training should be incorporated into the exercise routine at least 2 days per week. Hypoglycemia and extreme hyperglycemia can worsen if present at the time of exercise and should be corrected before proceeding with increased physical activity. Bariatric surgical procedures (restrictive and bypass) can be considered in obese patients with type 2 diabetes. Weight loss and diabetes remission rates are significant with these procedures, but the long-term benefits require additional studies.

Depression, anxiety, and diabetes-related stress are common among patients with diabetes and may impair their ability to achieve success with a diabetes management plan. Screening should occur continuously during the course of diabetes treatment.

\section{Pharmacologic Therapy}

An individualized treatment goal will help guide the selection of the optimal treatment regimen. For many persons with diabetes, a reasonable goal for hemoglobin A1c is less than $7.0 \%$ (or less than $6.5 \%$, if this can be achieved without significant hypoglycemia). If severe recurrent hypoglycemia is present, there is no recommended Hemoglobin A1c goal, as modification of the patient's diabetes regimen to resolve severe recurrent hypoglycemia should take precedence. The increased risks of hypoglycemia outweigh the risks of diabetes complications in older patients with longer disease duration, which necessitates consideration of a less-stringent glycemic goal.

\section{Therapy for type 1 diabetes mellitus}

Lifelong insulin therapy is the first-line treatment for type 1 diabetes. Physiologic insulin therapy, also known as intensive insulin therapy, is the ideal insulin regimen as it attempts to mimic the actions of normal pancreatic beta cells. Intensive insulin therapy includes multiple daily injections (MDI) ( $\geq 3$ per day) with intermediate or long-acting insulin for basal coverage and multiple pre-prandial injections throughout the day with analogue or regular insulin. Intensive insulin therapy can also include continuous subcutaneous insulin infusion (CSII) and meal-time boluses with an insulin pump. Data support targeting normal glycemic levels with a goal hemoglobin A1c of less than $7 \%$ for most persons with type 1diabetes to reduce long-term complications. Long-term physiologic insulin therapy reduces early microvascular disease by $34 \%$ to $76 \%$ and reduces cardiovascular events by $42 \%$ to $57 \%$. Intensive insulin therapy has risks, including significant increases in hypoglycemia and weight gain. Therapy should therefore be individually tailored for each patient's preferences, lifestyle, education level, financial resources, and co-morbidities.

Most persons with type 1 diabetes are sensitive to the effects of exogenous insulin therapy, with initial total daily doses of insulin typically ranging from 0.3 to $1 \mathrm{U} / \mathrm{kg} / \mathrm{d}$. A basal insulin doses should account for half of the total daily dose of insulin, while the remaining insulin should be divided to cover the number of meals consumed during the day. Basal insulin coverage can be provided with one to two daily injections of insulin detemir, glargine, or neutral protamine Hagedorn (NPH) insulin. CSII can also provide basal coverage with analogue insulin. For prandial coverage, analogue or regular insulin is injected prior to meal consumption or analogue insulin is bloused with CSII prior to meals. Insulin dosing immediately after a meal is appropriate in certain situations, particularly when food intake is unpredictable. Postprandial insulin dosing allows for a reduction in the insulin dose that is commensurate with the amount of food ingested to avoid hypoglycemia that could have resulted from the full insulin dose. For example, the postprandial insulin dose is reduced by $50 \%$ if only half of the meal is consumed.

\section{Therapy for type 2 diabetes}

Lifestyle modifications must often be combined with oral pharmacologic agents for optimal glycemic control, particularly as type 2 diabetes progresses with continued loss of pancreatic beta-cell function and insulin production. Multiple oral agents may be required or used in conjunction with noninsulin injectable agents or insulin as glycemic control worsens. There are many options for oral agents, with major differences in cost, timing of administration, mechanism of action, and side-effect profiles

Metformin is the recommended first-line therapy to be initiated either in conjunction with lifestyle modifications at the time of diagnosis or within 6 weeks of failing to obtain glycemic control with lifestyle changes alone. Metformin has a lower incidence of hypoglycemia and weight gain compared with some of the other oral agents and insulin. Gastrointestinal side effects (such as abdominal cramping or diarrhea) are common with 
metformin; initial low doses with gradual increases and administration of the tablet following a substantial meal can improve tolerance to the medication.

Due to the potential risk of lactic acidosis, contraindications to metformin therapy include serum creatinine greater than $1.5 \mathrm{mg} / \mathrm{dL}(133 \mu \mathrm{mol} / \mathrm{L})$ in men and $1.4 \mathrm{mg} / \mathrm{dL}(124 \mu \mathrm{mol} / \mathrm{L})$ in women, symptomatic heart failure or liver disease, and illness with hemodynamic instability.

Metformin must be withheld for 48hours in the setting of intravenous contrast dye. In hospitalized patient, metformin should be withheld with any illness that may cause dehydration.

If lifestyle modifications and maximally tolerated doses of metformin fail to adequately control glucose, additional agents should be added every 3 months until glycemic goals have been met. Without strong comparative-effectiveness data to identify the best class of second-line drugs to be implemented, several factors must be considered. Patient preferences and financial resources are key components to developing an individualized treatment plan. Another important determining factor in selection of the second-line drug class is the patient's weight. Weight-neutral drug classes include $\alpha$-glycosidase inhibitors and dipeptidyl peptidase-4 (DPP-4inhibitI weight loss is a desired effect, glucagon-like peptide 1 (GLP-1) mimetics, pramlintide, and sodium-glucose transporter-2 (SGLT2) inhibitors are candidates to consider. Weight gain is likely with the use of insulin, sulfonylureas, thiazolidinediones, and meglitinides. The risk of hypoglycemia must be considered with the selection of any therapeutic agent, particularly when it is combined with insulin secretagogues or insulin. Gastrointestinal side effects from GLP-1 mimetics and pramlintide may decrease tolerability for some patients and should not be used in patients with gastroparesis. Patients with frequent candidal genital infections would not be ideal candidates for SGLT2 inhibitor therapy.

Insulin therapy should be strongly considered in the setting of symptomatic hyperglycemia or markedly elevated hemoglobin Alc (>8.5\% to $9 \%)$ at the time of diagnosis or when lifestyle modifications and/or noninsulin therapies fail to achieve glycemic goals.

The American Association of Clinical Endocrinologists (AACE) recommends weight-based initiation of basal insulin at initial doses of 0.1 to $0.3 \mathrm{U} / \mathrm{kg}$. The dose should be increased several units every 2 to 3 days to reach fasting plasma glucose goals, based on the patient's SMBG( selfmonitoring of blood glucose) readings. Reductions of insulin doses by $10 \%$ to $40 \%$ should be made in the setting of hypoglycemia with insulin titrations.

If glycemic goals are not met with basal insulin, then prandial insulin should be added to the regimen with frequent titration of doses for optimal glucose control. When pre meal glucose values are not at a patient-specific goal, the preceding prandial insulin dose should be increased or decreased by $10 \%$ to $20 \%$ in the setting of hyper- or hypoglycemia, respectively.

\section{Complications}

1- Acute complications: Include diabetic ketoacidosis (DKA), hyperosmolar hyperglycemic syndrome (HHS), and hypoglycemia.

2- Late complications :The pathological hallmark of long-term complications of diabetes are due to microvascular and macrovascular complications that associated with chronic hyperglycemia, leading to damage and failure of varios organ systems such as eyes,nerves,kidneys, and the heart.

\section{Pathophysiology of Microvascular and Macrovascular Complications}

Several factors contribute to the development of microvascular and macrovascular complications such as:

Oxidative stress: These is caused by overproduction of ROS, it leads to elevated polyol activity, nonenzymatic glycation, and PKC level which in turn lead to the development of microvascular and macrovascular complications.

Advanced glycation products(AGEs): These are group of molecules formed by the nonenzymatic glycation of plasma proteins. These interfere with receptor function and block nitric oxide actitivity which contribute to the development of microvascular and macrovascular complications.Further, AGEs modify LDL particles and together with vascular damage accelerate atherosclerosis.

Low -grade inflammation: Hyperglycemia results in monocytes activation with induction of inflammatory mediators such as PKC and nuclear foctor-kB promoting oxidative stress.

Neovasculiration of vasa vasorum: the proliferation of vasa vasorum is associated with increased plaque bueden, which subsequently promotes atherosclerosis.

\section{Examples of Diabetic Microvascular and Macrovascular Complications Include}

\section{1-Ocular complications}

Diabetes has profound effects on the ocular tissues these include:

Diabetic retinopathy: It is a progressive blinding disease that affects 4.2 million people worldwide, making it a leading cause of blindness [25].It is more higher among people with TIDM, longer duration of diabetes, and among people of lower socioeconomic status.

Maculopathy: Macular involvement will result in blurring of vision. It is higher in T2DM.

Ischemic optic neuropathy: It is due to the impaired oxygen supply that results from the reduced retinal perfusion and micro aneurysms. This can lead to 
permanent vision loss.

Glaucoma: The prevalence of glaucoma in diabetics ranges from $4.96 \%$ to $14.6 \%(26)$.

Cataract: It is one of the main causes of vision impairment in diabetics.

\section{2-Diabetic nephropathy}

Diabetic nephropathy causes around $40 \%$ of cases of CKD requiring dialysis or kidney transplantation in the Western world [27].Classically patients first develop microalbuminuria, followed by macroalbuminuria during the first 15 years of diabetes. After that progressive loss of filtration rate develops.

\section{3-Cardiovascular disease (CVD)}

CVDs are the most prevalent cause of mortality and morbidity among people with diabetes; these include myocardial infarction and stroke

Adults with diabetes have 2-4times higher rates of mortality due to heart disease and stroke than adults without[28].

\section{4-Diabetic foot disease}

Diabetic foot disease occurs in all types of diabetes showing higher prevalence among males and in patients more than 60 years old[29].The burden of diabetic foot disease expected to rise in the future, giving that the prevalence of its predisposing factors-mainly the diabetic peripheral neuropathy and peripheral vascular disease are continually increasing[30].Other risk factors for diabetic foot disease include: foot deformities ,previous ulceration or amputation, long duration of diabetes, and associated co-morbidities.

\section{Diabetic Peripheral Neuropathy}

According to the International Consensus Group on Neuropathy; the diabetic neuropathy is defined as the detection of manifestations of peripheral nerves dysfunctions in diabetic patients, after excluding other causes of peripheral neuropathy [31]. Symptoms of diabetic peripheral neuropathy includes:

- Numbness.

- Tingling, pins and needle sensation.

- Burning pains usually at night.

- Lancinatig pain.

- hyperalgesia.

Patients may present with diabetic foot ulceration even without any preceding neuropathic complaints. The presence of diabetic peripheral neuropathy is the initiating factor of the development of foot ulceration in diabetics. The risk for diabetic foot ulceration increases by seven fold in patients with patients are diabetic peripheral neuropathy[32][33].It is also estimated that $45 \%$ to $60 \%$ of all ulcerations in diabetic mainly due to neuropathy, while $45 \%$ of the ulcers are due to combined neuropathic and ischemic factors[34][35].

Other type of diabetic neuropathies is autonomic neuropathy which leads to abnormal sweating and dry skin with cracking and fissuring facilitating the bacterial infection of the foot. More over autonomic neuropathy associated with thermoregulatory dysfunction, and abnormal tissue perfusion that further contribute to foot ulceration. Autonomic neuropathy is also associated with unexplained foot edema further adding to foot ulceration.

\section{Diagnosis of Diabetic Peripheral Neuropathy}

Diabetic peripheral neuropathy is diagnosed through careful patient history and physical examination of the feet. Using the combination of patient neuropathic symptoms, clinical signs, and electro diagnostic tests would be the best predictors for diabetic peripheral neuropathy. The following tests are commonly used:

Symptom scores: the most widely used one is Neuropathy Symptoms Score (NSS), showing high validity and sensitivity [36][37].

Semmes-Weinstein monofilament: It is widely used for the assessment of diabetic peripheral neuropathy. It assesses the protective ability (light touch and pressure).The most commonly used one is the $10-\mathrm{g}$ pressure monofilament (5.07 monofilament). The test done by application of gentle pressure on four planter sites(great toe and the base of the first, third and fifth metatarsals).Monofilament test has shown a sensitivity of $(66 \%-91 \%)$ in detection of diabetic patients at high risk for foot ulceration in several studies[38][39].

Vibration perception: Impairment of vibration perception is one of the earliest signs of diabetic peripheral neuropathy. It is usually tested with

$1-128 \mathrm{~Hz}$ tuning fork

2- Graduated rydel-seiffer tuning fork. The fork has 0-8 graded scale .It detect the presence of vibration perception impairment and the intensity of this impairment.

Tuning fork gives around $53 \%$ sensitivity. The reduction of vibration perception to less $4 / 8$ was present in $95 \%$ of diabetic foot ulcerations due to peripheral neuropathy [40][41].

Other methods for assessment which are not routinely used in clinical practice includes: nerve conduction studies, nerve biopsy, and skin biopsy.

\section{Peripheral Arterial Disease}

Peripheral arterial disease (PAD) is one of the macrovascular complication that highly prevalent in adult diabetic patients. PAD is a major cause of diabetic foot disease. The presence of PAD alters the normal response to foot ulceration and leads to persistent non-healing foot ulcers, where is an increased need for blood supply. PAD leads to progression of infection, increases tissue 
breakdown and insufficient delivery of oxygen, nutrition and antibiotics. All these factors further contribute to a potential foot amputations [42].Other risk factors of PAD includes: smoking, increasing age, hypertension, hyperlipidemia, and black race.

\section{Signs of Poor Blood Supply Include}

- Intermittent claudicating, Sharp leg cramps after walking usually in calf muscles, thighs, and buttocks,

- $\quad$ Pain in the feet even at rest

- $\quad$ Feet feeling cold

- Feet looking a reddish-blue color

- Cuts which slow to heel.

\section{Diagnosis of Peripheral Arterial Disease}

The ankle- brachial index: It is the ratio of the tibial systolic artery pressure to brachial systolic artery pressure. It is a simple and non-invasive bed- side screening test for the presence of peripheral arterial disease performed using a Doppler ultrasound; it has $95 \%$ sensitivity and $100 \%$ specificity for diagnosing PAD compared to the gold standard angiography. .ABI is calculated by dividing the ankle pressure over the highest brachial pressure, it assess the severity of peripheral arterial disease as it usually correlates with the patients reported symptoms and functiona1l status. The normal range of $\mathrm{ABI}$ is between 0.9 - 1.3. An ABI less than 0.9 is abnormal and indicates peripheral arterial disease. An ABI between 0.7 and 0.9 is mild disease, 0.5 and 0.79 is moderate, and less than 0,5 is considered severe disease. Falsely elevated values ABI can result in cases of calcified, non-compressible arteries. Thus the ABI may lead to underestimation of the severity of the disease in patients with diabetes [43].

The toe- brachial index: The toe- brachial index is calculated similar to ABI, where the systolic pressure is measured using a small cuff and a Doppler probe. Measuring the toe- brachial index is helpful in cases of ABI values less than 1.3 , as the small arteries of the lower limb are less likely to be calcified. A toe-brachial index less than 0.7 is diagnostic for PDA [44].Other tests includes: computed tomography angiography (CTA), contrast angiography, and transcutaneous oximetry.

Diabetic foot ulcer (DFU): $U$ is a break in the skin or a deep sore .It occurs primarily due to diabetic peripheral neuropathy together with variable contribution from (PAD), trauma, and superimposing foot infection [45][46].

Other risk factors associated with the development of DFU include: male gender, duration of diabetes longer than 10 years, advanced age, high body mass index , retinopathy, glycated hemoglobin level(HbAlc),foot deformities, high plantar pressure, and inappropriate foot self-care habits [47] [48].Cigarette smoking, diabetic nephropathy ,history of ulcer , and amputation are other risk factors,

It is estimated that approximately $20 \%$ of hospital admission among diabetic patients are due to diabetic foot ulcer [49]. Indeed, diabetic foot ulcer can lead to infection, gangrene, amputation and death if care is not provided [49]. Furthermore, DFU is responsible for substantial emotional and physical distress as well as productivity and financial losses that lower the quality of life [50] $7 \%$ to $20 \%$ of the total expenditure on diabetes in North America and Europe might be attributable to DFU [51].

Diabetic foot ulcers are classified into many classification systems, the two most widely used are: the Wagner [52] and University Texas systems [53].

\section{Wagner System Includes 6 Grades}

Grade 0: Pre- or Post- ulcerative site.

Grade 1: Superficial ulcer.

Grade 2: Ulcer penetrating to tendon or joint capsule.

Grade 3: Lesion involving deeper tissues.

Grade 4: Forefoot gangrene.

Grade 5: Whole foot gangrene involving more than twothirds of the foot.

\section{The University of Texas System Includes 4 Grades}

Grade 0: Pre- or post ulcerative site;

Grade 1: Superficial wound not involving tendon, capsule, or bone;

Grade 2: Wound penetrating to tendon or capsule

Grade 3: Ulcer penetrating to bone or joint.

\section{Lower Limb Amputations}

Peripheral vascular diseases and peripheral neuropathy lead to foot infection and ulcers which may lead to amputations

Overall, the rate of lower limb amputation in diabetics is $15 \%$ higher than non-diabetics. Approximately $50 \%-70 \%$ of all lower limb amputations are due to diabetic foot ulcer [54].In addition, it was reported that every 30 second one leg is amputated due to DFU worldwide[55].

Peripheral neuropathy, ulceration, infection, and peripheral vascular disease are the principal factors for ulcer complications and amputation in diabetic patients [56][57].Structured healthcare is one of the most effective approaches to reducing the indicators for diabetic foot amputation, and studies have shown that these can be reduced by as much as $75 \%$ [57] .

Factors such as low socioeconomic status, smoking [58][59], gender, renal impairment[60], ischemia, diabetic neuropathy[61] and high levels of glucose and triglycerides [62] have been reported as importantly associated with the risk of foot amputation.

\section{Foot Infections}

These include: cellulites, abscesses, wet gangrene, necrotizing fasciitis, tineapedis, fungal infection of the nails, and osteomyelitis. 
Cellulitis: presence of the swelling, erythematic and hotness, those mean an inflammatory reaction. Irrespective of the cause invasion and multiplication of micro-organisms in body and in the tissues, which may be clinically in apparent or result in local cellular injury due to competitive metabolism, toxins release, and intracellular replication, or immune response

Gangrene: A continuous necrosis of the skin and underlying structures (muscles, tendon, joint or bone), due to a lack of blood indicating irreversible damage where healing cannot be anticipated without loss of some part of the extremity.

Fungal infection of the nails: Which become yellow-brown or opaque, thick and brittle, and may separate from the rest of the nail? In some cases, the nail may crumble. The dark moist and warm environment of shoes in addition to, the injury to the nail.

Tineapedis (Athletes foot): It is fungal infection of the foot causes itching, redness, and cracking.

Charcot neuroarthropathy: It is progressive degeneration of a weight bearing joint, a process marked by bony destruction, bone resorption, and eventual deformity. Onset is usually insidious.

Calluses: A callus is a build-up of hard skin, usually on the underside of the foot caused by improperly fitting shoes or by a skin abnormality.

Corns: Acorn is a build-up of hard skin near a bony area of a toe or between toes, it caused by too much rubbing or pressure on the same spot.

Blisters: Are area of skin that are raised and fill with fluids which can be infected usually occurred due to unfitted shoes or wearing shoes without socks.

Bunions:It is a bump at the outside of the big toe. It is usually results from high- heeled, pointed shoes with narrow toes. These shoes put pressure on the big toe, pushing it toward the second toe, it is often runs in families.

Ingrown toenails: It happens when the edges of toenail grow in the skin. It occurred with wearing too tight shoes and cutting into the corner of the toenails causing redness, swelling, pain, drainage, and. Infection.

Hammertoes: Hammertoes are toes that curl under feet, it is usually due to muscle weakness that caused by nerve damage, it run in family, and caused by too short shoes .Hammertoes can cause problems with walking and can lead to other foot problems, such as blisters, calluses, and sores.

Dry and cracked skin: It is rough, scaly and flaking skin. it is caused by nerve damage, or poor blood flow.

\section{Treatment and prevention of diabetic foot lesions}

An effective plan for proper diabetic foot syndrome prevention and treatment needs a multidisciplinary team approach. This team approach includes:

1- Diabetologist/Endocrinologist t: To optimize the metabolic control of the diabetics.
2- Diabetic educator and qualified nurse: To provide special education and reassurance.

3- Podiatrist: Who guides the patients to prevent diabetic foot lesions?

4- Orthotics': To help in choosing the appropriate feet wear or custom feet wear to allow adequate pressure distribution and thus rapid wound healing.

5- Vascular surgeon: To assess the vascularity of the lower limbs and provide interventional management whenever required.

6- Infection disease specialist: For appropriate choice of antibiotics, based on the culture results.

7- Nutritionist: to help in adequate glycemic control, weight loss , and wound healing.

The American Diabetes Association defined a preventive care team as a multidisciplinary team, can decrease the risks associated with diabetic foot ulcer and amputation by $50-85 \%$.A good strategy regarding diabetic foot care include: Patient education, good glycemic control, foot examination and proper DFU treatment

1-Education: $t$ has been shown that up to $50 \%$ of DFU cases can be prevented by effective education. Education on foot-self management is considered the cornerstone to prevent diabetic foot ulcer. The ultimate aim of foot care education for diabetics is to prevent foot ulcer and amputation.

Patients should be educated about the risk factors and importance of foot care. These includes:

- Follow up health care provider regarding nutrition, exercise, and medication.

- Washing the feet daily, in warm water, using a mild soap, Test the temperature of the water with the elbow, because nerve damage can affect sensation in the hands. Do not soak the feet. Dry the feet well, especially between the toes.

- $\quad$ Check the feet daily for sores, calluses, and redness.

- Keep the skin of the feet moist by applying lotion. Do not put lotion between toes.

- Gently smooth - corns and calluses with an emery board or pumice stone, do it after shower, and move the emery board in only one direction.

- Check the toenails once a week .Trim toenails with clipper straight across, and smooth it with a nail file.

- Always wear closed- toed shoes or slippers. Do not wear sandals and do not wail barefoot.

- Always wear soft elastic socks or stocking that fit the feet well.

- Use shoes made of canvas or leather that fit the feet well. Extra wide shoes for people with deformities.

- Always checking inside the feet, for objects.

- Protect the feet from heat and cold.

- Keeping the blood to flow by putting the feet up when sitting, and move the ankle s several times.

- $\quad$ Stop smoking.

- An annual foot examination should be carried out. 
- Follow-up with the podiatrist every two to three months.

2-Blood sugar control: Glucose control is the most important metabolic factor. Monitoring of blood glucose is best done by checking HbA1c. Inadequate control of blood sugar is the primary cause of diabetic foot ulcer [63]. Pomposelli et al found that patients with blood glucose level $>220 \mathrm{mg} / \mathrm{dl}$ had infection rates that were 2.7 times higher than for patients with lower readings [64].Moreover $1 \%$ mean reduction in $\mathrm{HbAlc}$ was associated with a $25 \%$ reduction in microvascular complications including neuropathy [64]. It has been shown that for every $1 \%$ increase in $\mathrm{HbAlc}$, there is an increase of $25 \%-28 \%$ in the relative risk of peripheral arterial disease which is a primary cause of diabetic foot ulcer.

3-Foot examination: Comprehensive foot examination includes:

- Observation of the colour, temperature, dryness, edema .and nails.

- Looking for signs of infection: These include redness, hotness, tenderness, and swelling.

- $\quad$ Checking of the arterial pulses(dorsalis pedis artery pulse, posterior tibial artery pulse)

- Inspection of blisters breaks in the skin, callus, pressure sign, and ulcers.

- Looking for deformities such as: clawed toes, hallux valgus, hammer toes, Charcot foot, and nail deformities.

- Checking for sensation by: cotton wool, $10 \mathrm{~g}$ monofilament, tuning fork.

4-Management of diabetic foot ulcer: his includes debridement, off-loading, dressings, treatment of infection, and application of other new therapies.

Debridement: $t$ is the removal of necrotic, infected, and dead tissues from the wound. It is the most important measure in treating DFU, leading to wound healing and decreasing the possibility of limb amputation. There are different kinds of debridement for patient with diabetic foot ulcer.

1-Surgical: It is the gold standard method in diabetic foot ulceration. To obtain optimal results, healthy tissue loss should be minimized, foot function should be preserved, and deformities which can precipitate recurrence of foot ulcers should be prevented. Surgical debridement is mainly done for ulcers with large amount of necrotic and non-viable tissues. Debridement is performed using a scalpel blade with the tip pointed in a45- degree angle or a tissue nipper to remove all necrotic and non-viable tissues until bleeding healthy base is obtained [64].

2-Mechanical: This method includes wet to dry dressings, high pressure irrigation, pulsed lavage and hydrotherapy.

3-Autolytic: this method occurs naturally in a healthy moist wound environment when arterial perfusion and venous drainage are maintained.

4-Enzymatic: Like streptokinase this enzyme aggressively digests fibrin, collagen, and elastin, which are commonly found in the necrotic exudates of the wound.

5-Biological: Sterile maggots of the green bottle fly (Lucilia sericata) are placed directly into the wound and covered by close net dressing. The larvae have ferocious appetite for necrotic material while avoiding newly formed healthy tissue.

\section{Offloading}

The use of offloading techniques, commonly known as pressure modulation is considered the most important part in management of neuropathic ulcers .Recent studies showed that proper offloading promotes DFU healing [64].

There are different types of offloading modalities, their choice determined by the severity of ulcer, location of ulcer and the patient compliance. Common offloading techniques include:

1- Casting techniques: Example is the total contact casts which is the most effective for the treatment of neuropathic ulcers.

2- Foot wear related techniques: Examples: Shoes or half shoes, sandals, insoles, and in-shoe orthoses.

3- Surgical offloading techniques: These include: liquid silicone injections, tissue augmentation, callus debridement, and metatarsal head resection/osteotomy/arthroplasty/exostectomy.

\section{Advanced dressing}

Ideal dressings should confer moisture balance, protease sequestration, growth factor stimulation, antimicrobial activity, oxygen permeability, and promotion of autolytic depridement. There are two types of advanced dressing:

1- Hydrocolloids: These usually composed of hydrocolloid matrix bonded onto a vapor preamble film or foam backing. Examples include: Duoderm, Granuflex, and Comfeel.

2- Hydrogels: These dressings consist of cross-linked insoluble polymers and up to $96 \%$ water. They are designed to absorb wound exudates or rehydrate a wound, depending on the wound moisture. Examples include: Aquaform gel and intrasite gel.

Hyperbaric oxygen therapy: is therapy has shown promise in the treatment of resistant non-healing diabetic foot ulcers [65].It involves intermittent administration of $100 \%$ oxygen, usually in daily sessions.

Electrical stimulation: Has been reported as a perfect adjunctive therapy for DFU healing. In study conducted by Peters et al on 40 patients with diabetic foot ulcer, significant differences in number of healing ulcers were found at 12 weeks.

Negative pressure wound therapy: his therapy is a non-invasive wound closure system that uses controlled 
localized negative pressure .This system uses latex-free and sterile polyurethane orpolyvinyl alcohol foam.

Bioengineered skin: his method replaces the degraded and destructive milieu of extracellular matrix with the introduction of a new ground substance matrix with cellular components to of start a new healing trajectory. Currently, three kinds of electrical stimulation products were approved in the United States for treating diabetic foot ulcer .These include:

1- Apligraf: Abilayered living-skin constructs containing an outer layer of allogenic human keratocytes and second layer allogenic fibroblasts.

2- Dermagraft: An allogenic living-dermis equivalent and includes neonatal fibroblasts.

Growth factor: DFU has shown the benefits from growth factors such as platelet derived growth factor, insulin-like growth factors, fibroblast growth factors, endothelial growth factors, and epidermal growth factors.

Treatment of infections: Infections must be diagnosed and treated promptly and adequately as they may rapidly progress to a limb-threatening condition .Moreover, high levels of bacteria can delay or even prevent wound healing.

\section{5-Treatment and prevention of other foot problems}

Blisters: Can be avoided by using socks and wearing properly fit shoes. When occur, blisters should not be opened. Treatment cleaning soft bandages, and antibiotics use.

Bunions: Can be prevented by avoiding wearing high-heeled shoes and using of felt or foam padding. If the bunion causes severe pain or deformity, surgery is advised.

Corns and calluses: Can prevented by wearing properly fit shoes .If occurs avoid cutting with sharp objects. Pumice stone can be used for removal of the build -up of tissues.

Hammertoes: Avoiding too short shoes can help in prevention. Splinting and corrective footwear can help treating them. Surgery to straighten the toe is needed in severe cases.

Ingrowing nails: Proper trimming of the toenails is best way of prevention. Surgery sometimes is needed for removal of ingrowing part.

Athlete foot: Daily washing and proper dryness help in prevention. treatment by anti-fungal .

Several studies were done regarding diabetic foot care. In one study carried out in Sudan by Maali .M , Mohamed .H., conducted in Jabir Abu-alaiz Diabetic Centre in the Khartoum state in 2014,about diabetic foot lesions predicting factors. Foot care Knowledge level ( $\mathrm{P}$ $<0.0005)$ O.R $=0.2,95 \%$ CI $(0,9-0.4)$ both proved to be significant contributions to development of diabetic foot lesions They found that foot care knowledge and diabetes mellitus duration were important predicting factors for diabetic foot lesions. They also noted poor knowledge of participants about foot care and infrequent visits to foot care clinics. They conclude that acquiring knowledge is important, and diabetics with a long history of diabetes mellitus need to raise their threshold for promoting foot health, prevention, and protection from diabetic foot lesions/.

Study about Knowledge, Practice, and Barriers of Foot Care among Diabetic Patients Attending Felege Hiwot Referral Hospital, Bahir Dar, Northwest Ethiopia. Institution based descriptive cross-sectional study was conducted from March 1 to April 1, 2014. A total sample of 313 diabetic patients was recruited from both inpatient and outpatient medical department using convenient sampling technique, study participants were consecutively interviewed till final sample sized was reached. The study concludes that the prevalence of diabetes is increasing in rural communities and farmers. Generally half of the study participants have good knowledge of foot care, half of diabetic patients poorly practice proper foot care. Physicians/nurses gave less attention to foot examination. Respondents had good foot care practice in the area of washing of feet and not walking barefoot.

Another study about diabetic foot prevalence, Knowledge, and foot self- care practice among diabetic patients in Dar el Salaam, Tanzania- across- sectional study, 404 diabetic patients were included in the study, $15 \%$ had foot ulcers, $44 \%$ had peripheral vascular disease. The mean knowledge score was $11.2 \pm 6.4$ out of a total possible score of 23.Low mean scores were associated with lack of formal education

$(8.3 \pm 6.1)$. Among the 404 patients, $48 \%$ had received advice on foot care, and $72.5 \%$ had their feet examined by a doctor at least once since diagnosis. Foot self- care was significantly higher in patients who had received advice on foot care and in those whose feet had been examined by a doctor at least once. It conclude that the prevalence of diabetic foot is high, and there is an urgent need to establish coordinated foot care services within the diabetic clinic to identify feet at risk, institute early management, and provide continuous foot care education to patients and health care provider

Study about foot care knowledge and practice of diabetic patients in Saudi Arabia done in November- 2016 by Yahya M.Solan, et al. They found that the prevalence of foot among males and females was 58\% and 52.9\% , respectively. Eighteen percent of the study population has history of foot ulcer. Almost 53.6\% patients had good foot care knowledge. Males were more adherent to foot drying by $65.2 \%$, while females are applying more attention to softening of skin by $72.3 \%$. There were no significance between males and females regarding foot inspection, nail care, adherent to medication and shoes check. it conclude that , the knowledge and practice of foot care among diabetic patients were not adequate .

Other Study about knowledge and practice regarding foot care and the prevalence of peripheral neuropathy Among diabetic patients visiting a secondary Care Rural Hospital in southern India by Hanu Geprge and et al, 
conclude that there is exist deficiencies in knowledge and practice regarding foot care foot care, and $72.5 \%$ had their feet examined by a doctor at least once since diagnosis. Foot self- care was significantly higher in patients who had received advice on foot care and in those whose feet had been examined by a doctor at least once. It conclude that the prevalence of diabetic foot is high, and there is an urgent need to establish coordinated foot care services within the diabetic clinic to identify feet at risk, institute early management, and provide continuous foot care education to patients and health care providers

\section{Material and Methods}

\subsection{Research Design}

Study design: This is and observational, descriptive, cross-sectional hospital-based study.

Study area: The study was conducted in the diabetes clinic in Al Ribat University Hospital, Khartoum State Sudan. It is belonging to the ministry of interior. It provides health services to police force and their families and other sectors of the community.

Study duration: The study was conducted in the period between October \& December 2016.

Study population: All diabetic patients type 2 between $40-80$ years age attending diabetic clinic in

Al Ribat University Hospital between October \& December 2016.

Inclusion criteria: All patients with type 2 diabetes age between $40-80$ years old.

Exclusion criteria: Any severely ill patient.

\subsection{Data Collections Tool}

Closed ended structured questionnaire was filled by the researcher to collect data from patients. The final version of the questionnaire consisted of 46 classified into main seven sections. Section one contains sociodemographic background (age, sex, smoking).The second section includes information about diabetes like duration of the disease, adherent to diabetic diet, exercise, type of therapy, and co-morbidity. The third part questions about foot lesions. The fourth and fifth sections include questions about knowledge and attitude about foot care. The six sections include questions about practice about foot care. The seven sections include the examination. The researcher collected the information using face to face interview with closed ended questions.

Sample size: Total coverage of 156 type 2 diabetic patients' age 40-80years old.

Sampling technique: The sampling procedure of this study was total coverage sampling for type 2 diabetic patients attended diabetic clinic in Al Ribat Teaching Hospital during data collection period from October 2016 to December 2016.

\section{Material Used for Examination}

- Cotton woo land pin prick for testing touch and pain sensation.

- Tuning fork $(128 \mathrm{~Hz})$ for vibration.

- Weight and height scale for BMI.

- Sphygmomanometer for checking Blood Pressure.

- The peripheral arterial pulse was checked by feeling the dorsalis pedis and posterior tibial artery pulses.

\section{Study Variables}

Dependent variable includes:

- Foot problems

- Knowledge

- Attitude

- Practice

Independent variables include

- Socio-Demographic characteristics ( age, gender, smoking)

- Co-morbidities

- Exercise

- Adherent to diabetic diet

- Duration of diabetes

- $\quad$ Type of therapy

\section{Data Analysis}

Data were reviewed carefully to verify that there are no data mistakes. The Statistical Package for the Social Sciences software program (SPSS version 21) was used for data analysis by biostatistician. Frequency distributions were obtained and descriptive statistics were calculated. Knowledge was measured using 4 question, attitude 3 questions, and 14 questions for foot care practice in the area of feet washing techniques, skin and nail care, and foot wear care.

Each "yes" answer carried one point and zero point for a " no". The level of (knowledge, attitude, practice) was determined based on the mean score as follows:

- $\quad>70 \%$ given for good

- $50-70 \%$ for moderate

- $<50 \%$ for bad.

Another level of data analysis was conducted using Chisquare test to test some associations, a P Value less than 0.05 was considered significant.

The results were presented in tables and figures.

\section{Expected Outcomes}

Average foot care knowledge.

Poor attitude and practice about foot care.

Association between foot lesions and proper foot care 


\section{Ethical Considerations}

Ethical approval was obtained from:

1- Sudan Medical Specialization Board (SMSD).

2- Al-Ribat University Hospital administration for approval and ethical clearance.

3- All participants were consented using informed and written consent. Serial numbers rather than names were used, and the right to refuse or terminate at any point of the interview was assured.

\section{Results}

A total number of 156 patients with T2DM were enrolled in this study, with a response rate of $100 \%$ as consecutive respondents were recruited until the sample size was reached .All the patients agreed for participation in the study. All the questionnaires were filled by the researcher.

\section{Socio-demographic Characteristics of the Population}

$117(75 \%)$ of the patients were females while $39(25 \%)$ were males as shown in (Figure 1).

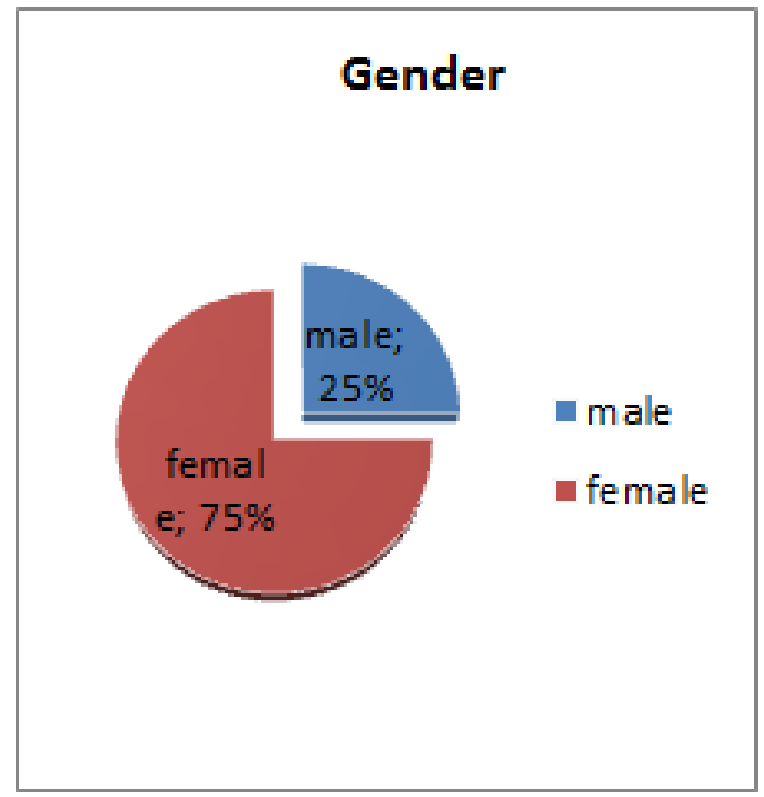

Figure 1. Gender distribution among study population $(\mathrm{n}=156)$

Regarding the age, half of patients $(50 \%)$ were ranged from 50-59 years with mean (SD) age of 53.4 (7.68) years as shown in (Figure 2).

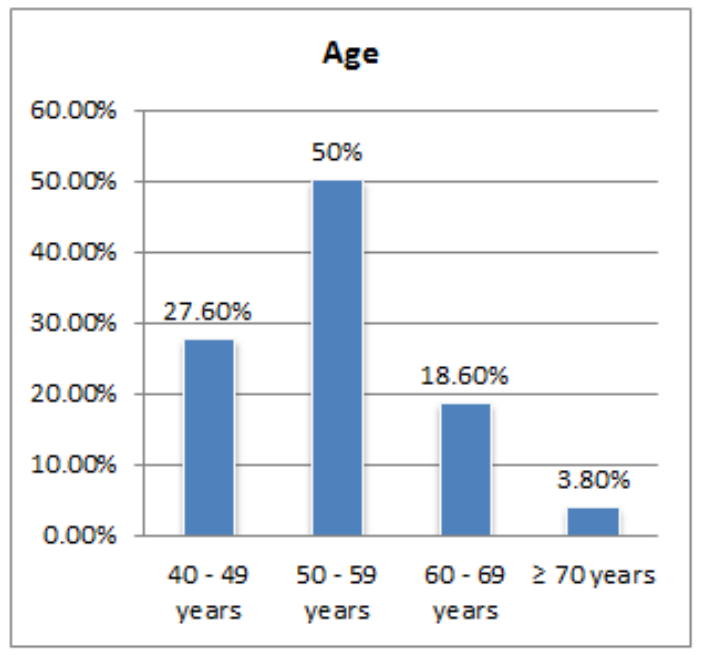

Figure 2. Age distribution among study population $(n=156)$.

Regarding smoking $20(12,8 \%)$ of the patients are smoking, all of them are males. Shown in figure 3.

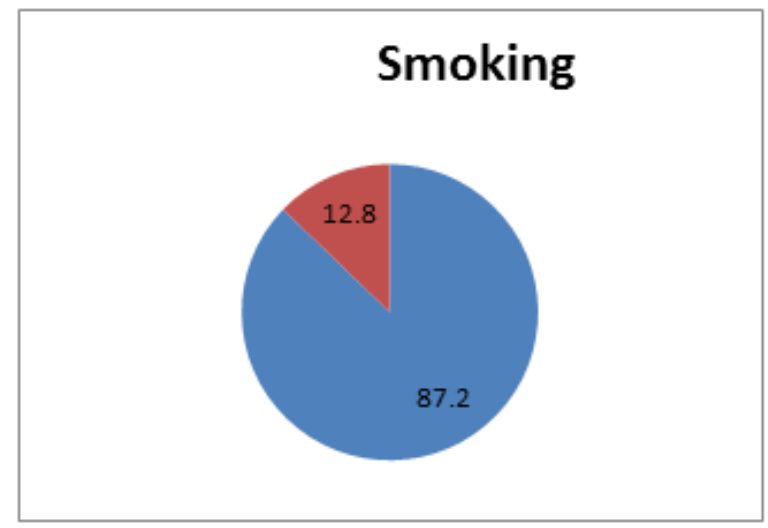

Figure 3. Smoking habit among study population $(n=156)$.

In clinical history, the mean of diabetes duration was $8.89(5.17)$ years and the majority $60(38.5 \%)$ of them had the disease within the period of $5-10$ years. $67(42.9 \%)$ were adherent to the diabetic diet. According to the types of therapy used, 81 (51.9) were use insulin, 60 (38.5\%) were use oral hypoglycemic drugs and $15(9.6 \%)$ of them were use diet control. $40(25.6 \%)$ of the participants were performed exercise. On co-morbidity, most of the participants $61(56.5 \%)$ were with hypertension followed by; hyperlipidemia in 22 (20.4\%), ischemic heart disease in $17(15.8 \%)$, hypothyroidism in $2(1.8 \%)$, also hyperthyroidism in $2(1.8 \%)$ and chronic kidney disease in one $(0.9 \%)$ participant. $20(12.8 \%)$ of the participants were smokers as shown in (Table 1). 
Table 1. Shows the disease history of the patients $(n=156)$

\begin{tabular}{|c|c|c|}
\hline & $\mathbf{N}$ & $\%$ \\
\hline \multicolumn{3}{|l|}{ Duration of disease mean $(\mathrm{SD})=8.89(5.17)$} \\
\hline$<5$ years & 37 & 23.7 \\
\hline $5-10$ years & 60 & 38.5 \\
\hline$>10$ years & 59 & 37.8 \\
\hline Adherents to diabetic diet (Yes) & 67 & 42.9 \\
\hline \multicolumn{3}{|l|}{ Type of therapy } \\
\hline Diet only & 15 & 9.6 \\
\hline Oral hypoglycemic agent & 60 & 38.5 \\
\hline Insulin & 81 & 51.9 \\
\hline Exercise (Yes) & 40 & 25.6 \\
\hline \multicolumn{3}{|l|}{ Co-morbidity $(\mathrm{n}=108)$} \\
\hline$H T N$ & 61 & 56.5 \\
\hline$I H D$ & 17 & 15.8 \\
\hline Hyperlipidemia & 22 & 20.4 \\
\hline Hypothyroidism & 3 & 2.8 \\
\hline Hyperthyroidism & 2 & 1.8 \\
\hline Asthma & 2 & 1.8 \\
\hline$C K D$ & 1 & 0.9 \\
\hline Smoker & 20 & 12.8 \\
\hline
\end{tabular}

\section{History of Patients with T2DM}

Regarding history and clinical examination of the patients, $12(7.7 \%)$ of them had foot ulcers, $6(3.8 \%)$ had leg sore or cut took 2 weeks to heal, $6(3.8 \%)$ have ulcers, blisters or sore in their feet, $3(1.9 \%)$ had discharge or blood in their socks, 9 (5.8\%) had feet calluses, 88 (56.4\%) had feet numbness, tingling and needles sensation or itching and $66(42.3 \%)$ of them had tightness, pain or cramps in their feet as shown in (Table 2).

Table 2. Shows the feet problems of the study group $(n=156)$.

\begin{tabular}{|c|c|c|}
\hline & $\mathrm{N}$ & $\%$ \\
\hline Patients had foot ulcers & 12 & 7.7 \\
\hline Patients had leg sore or cut took 2 weeks to heal & 6 & 3.8 \\
\hline Patients have ulcers, blisters or sore in their feet & 6 & 3.8 \\
\hline Patients have discharge or blood in their socks & 3 & 1.9 \\
\hline Patients have feet calluses & 9 & 5.8 \\
\hline $\begin{array}{c}\text { Patients have feet numbness, tingling and needles } \\
\text { sensation or itching }\end{array}$ & 88 & 56.4 \\
\hline Patients have tightness, pain or cramps in their feet & 66 & 42.3 \\
\hline
\end{tabular}

Among 12 (7.7\%) of the patients had feet ulcers, 9 out of $12(75 \%)$ had loss of sensation and 10 out of $12(83.3 \%)$ had palpable feet pulse. In $6(3.8 \%)$ had leg sore or cut took 2 weeks to heal, 4 out of $12(66.7 \%)$ had intact sensation and 4 out of $6(66.7 \%)$ had palpable feet pulse. Also, among $6(3.8 \%)$ had ulcers, blisters or sore in their feet, 3 out of $6(50 \%)$ had intact sensation and 4 out of $6(66.7 \%)$ had palpable feet pulse. In 3 (1.9\%) had discharge or blood in their socks, all of them 3 out of $3(100 \%)$ had no intact sensation and 2 out of $3(75 \%)$ had impalpable feet pulse. In $9(5.8 \%)$ had feet calluses, 7 out of $9(77.8 \%)$ had intact sensation and also 7 out of 9 (77.8\%) had impalpable feet pulse (Table $3 \& 4$ ).
Table 3. sensation in patients having foot ulcers

\begin{tabular}{|c|c|c|c|}
\hline & \multicolumn{2}{|c|}{ Sensation (intact) } & \multirow{2}{*}{ P. value } \\
\hline Patients had foot ulcers & $3(25 \%)$ & $9(75)$ & 0.030 \\
\hline $\begin{array}{c}\text { Patients had leg sore or cut took } \\
\text { 2 weeks to heal }\end{array}$ & $\begin{array}{c}4(66.7 \\
\%)\end{array}$ & $\begin{array}{c}2 \\
(33.7 \%)\end{array}$ & 0.035 \\
\cline { 1 - 2 } $\begin{array}{c}\text { Patients have ulcers, blisters or } \\
\text { sore in their feet }\end{array}$ & $3(50 \%)$ & $3(50 \%)$ & 1.0 \\
\hline $\begin{array}{c}\text { Patients have discharge or } \\
\text { blood in their socks }\end{array}$ & $0(0)$ & $\begin{array}{c}3 \\
(100 \%)\end{array}$ & 0.002 \\
\hline Patients have feet calluses & $\begin{array}{c}7 \\
(77.8 \%)\end{array}$ & $\begin{array}{c}2 \\
(22.2 \%)\end{array}$ & 0.02 \\
\hline
\end{tabular}

Table 4. feet pulse in patients having foot ulcers

\begin{tabular}{|c|c|c|c|}
\hline & \multicolumn{2}{|c|}{ Feet pulse } & \multirow{2}{*}{ P. value } \\
\hline & Palpable & Impalpabe & \\
\hline Patients had foot ulcers & $\begin{array}{c}10 \\
(83.3 \%)\end{array}$ & $2(16.7 \%)$ & 0.000 \\
\hline $\begin{array}{l}\text { Patients had leg sore or } \\
\text { cut took } 2 \text { weeks to heal }\end{array}$ & $4(66.7 \%)$ & $2(33.7 \%)$ & 0.03 \\
\hline $\begin{array}{c}\text { Patients have ulcers, } \\
\text { blisters or sore in their } \\
\text { feet }\end{array}$ & $4(66.7 \%)$ & $2(33.7 \%)$ & 0.03 \\
\hline $\begin{array}{l}\text { Patients have discharge } \\
\text { or blood in their socks }\end{array}$ & $1(25 \%)$ & $2(75 \%)$ & 0.03 \\
\hline $\begin{array}{l}\text { Patients have feet } \\
\text { calluses }\end{array}$ & $7(77.8 \%)$ & $2(22.2 \%)$ & 0.02 \\
\hline
\end{tabular}

\section{Clinical Examination in Patients with T2DM}

In the examinations, the mean of the BMI was 29.45 (3.76) and the majority of them $86(55.1 \%)$ were overweight. Regarding to blood pressure, the majority of the patients $88(56.4 \%)$ had systolic BP less than 140 $\mathrm{mm} / \mathrm{Hg}$, also the majority of them $104(66.7 \%)$ had diastolic BP less than $90 \mathrm{~mm} / \mathrm{Hg}$. Concerning to feet examination, $6(3.8 \%)$ of the patients had ulcerations, 6 (3.8\%) had infections, 7 (4.5\%) had amputations, 153 (98.1\%) had intact sensation and $154(98.7 \%)$ had palpable feet pulse as shown in (Table 5).

Table 5. Shows the clinical examination of the patients $(n=156)$

\begin{tabular}{|c|c|c|}
\hline Examination & $\mathbf{N}$ & $\mathbf{\%}$ \\
\hline BMI, mean (SD)=29.45 (3.76) & & \\
\hline Normal & 15 & 9.6 \\
\hline Overweight & 86 & 55.1 \\
\hline Obese & 55 & 35.3 \\
\hline Systolic BP (mm/Hg) & & \\
\hline$<140$ & 88 & 56.4 \\
\hline$\geq 140$ & 68 & 43.6 \\
\hline Diastolic BP (mm/Hg) & & \\
\hline$<90$ & 104 & 66.7 \\
\hline$\geq 90$ & 52 & 33.3 \\
\hline Foot examination & & \\
\hline Deformities (Yes) & 0 & 0 \\
\hline Abrasions (Yes) & 0 & 0 \\
\hline Ulcerations (Yes) & 6 & 3.8 \\
\hline Diabetic septic foot (Yes) & 6 & 3.8 \\
\hline Amputations toes(Yes) & 7 & 4.5 \\
\hline Sensation (Intact) & 139 & 89.1 \\
\hline Foot pulse (Palpable) & 154 & 98.7 \\
\hline
\end{tabular}




\section{Knowledge about Foot Care among Patients with T2DM}

patients aware about foot care, $98(62.8 \%)$ of the total number of study population aware of that loss of feet sensation can lead to feet ulcer, $88(56.4 \%)$ know reduction of blood can lead to feet ulcer, $116(74.4 \%)$ know infection of feet may develop to gangrene and $43(27.6 \%)$ of them knows that smoking can reduced blood flow to feet as shown in (Table 6).

Table 6. Shows the knowledge about foot care among patients with T2DM.

\begin{tabular}{|c|c|c|}
\hline & $\mathrm{N}$ & $\%$ \\
\hline $\begin{array}{c}\text { Patients who knows loss of feet sensation can lead to } \\
\text { feet ulcer }\end{array}$ & 98 & 62.8 \\
\hline $\begin{array}{c}\text { Patients knows reduction of blood can lead to feet } \\
\text { ulcer }\end{array}$ & 88 & 56.4 \\
\hline $\begin{array}{c}\text { Patients knows infection of feet may developed to } \\
\text { gangrene }\end{array}$ & 116 & 74.4 \\
\hline $\begin{array}{c}\text { Patients knows that smoking can reduced blood flow } \\
\text { to feet }\end{array}$ & 43 & 27.6 \\
\hline \begin{tabular}{c} 
Pang \\
\hline
\end{tabular}
\end{tabular}

Patient's knowledge about foot care, 88 (56.4\%) had good knowledge, $62(39.7 \%)$ had bad knowledge and 6 $(3.8 \%)$ had moderate knowledge as shown in (Table 7).

Table 7. Shows the knowledge about foot care levels distribution of the study group $(\mathrm{n}=156)$

\begin{tabular}{|c|c|c|}
\hline & $\mathrm{N}$ & $\%$ \\
\hline Bad knowledge & 62 & 39.7 \\
\hline Moderate knowledge & 6 & 3.8 \\
\hline Good knowledge & 88 & 56.4 \\
\hline
\end{tabular}

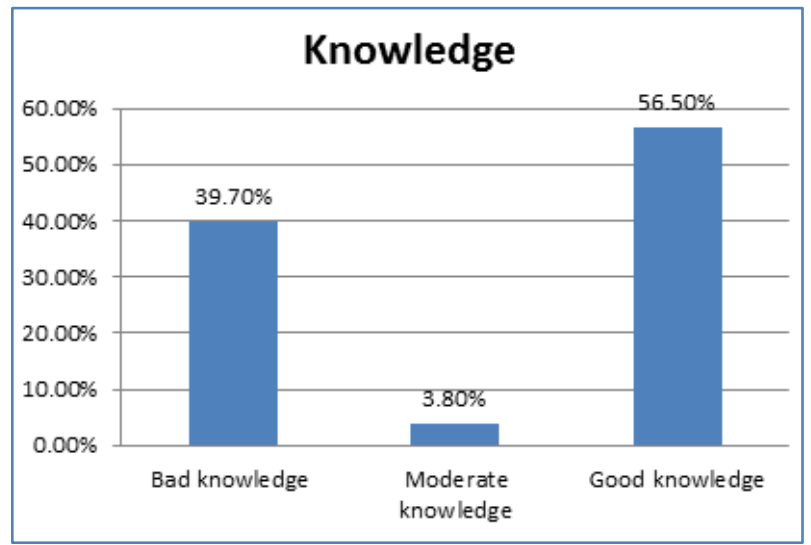

Figure 4. Knowledge about foot care $(n=156)$.

\section{Attitude Foot Care among Patients with T2DM}

Regarding patients attitude about foot care, 40 (25.6\%) of the total number of study population were given foot care information and $22(14.1 \%)$ of them read handouts on foot care. Considering nail trimming, 88 (56.4\%) cut their nails straight though and $68(43.6 \%)$ cut them along the edges as shown in (Table 8).
Table 8. Shows the attitude about foot care of the study group toward diabetic foot care $(n=156)$

\begin{tabular}{|c|c|c|}
\hline & $\mathbf{N}$ & $\mathbf{\%}$ \\
\hline Patients who given foot care information & 40 & 25.6 \\
\hline Patients who read handouts on foot care & 22 & 14.1 \\
\hline Ways of nails trimming: & & \\
\hline Cutting along the edges & 68 & 43.6 \\
\hline Cutting straight through & 88 & 56.4 \\
\hline
\end{tabular}

Regarding attitude about foot care, $110(70.5 \%)$ had bad attitude, 30 (19.2\%) had moderate attitude and $16(10.3 \%)$ had good attitude as shown in (table 9).

Table 9. Attitude about foot care levels distribution of the study group $(\mathrm{n}=156)$

\begin{tabular}{|c|c|c|}
\hline & $\mathrm{N}$ & $\%$ \\
\hline Bad attitude & 110 & 70.5 \\
\hline Moderate attitude & 30 & 19.2 \\
\hline Good attitude & 16 & 10.3 \\
\hline
\end{tabular}

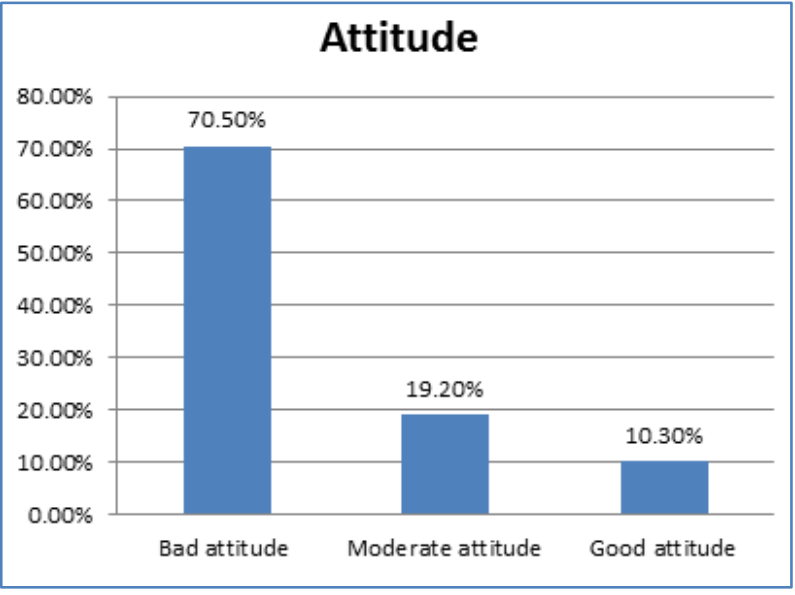

Figure 5. Attitude about foot care $(n=156)$.

\section{Practice of Foot Care among Patients with T2DM}

Regarding patients practice about foot care, 134 of the total number of study population $(85.9 \%)$ examined their feet daily. 152 (97.4\%) wash their feet daily. 37 (23.7\%) dried between their toes. $47(30.1 \%)$ use moisturizing cream to their feet. $126(80.8 \%)$ cut their toenails by themselves while $30(19.2 \%)$ cut their toenails by one of their family members. 10 (6.4\%) soak their feet. $19(12.2 \%)$ tested water temperature before putting their feet in it. Only $3(1.9 \%)$ walk around bare feet. $73(46.8 \%)$ wore shoes without socks. $95(60.9 \%)$ inspect their shoes for foreign objects. 6 (3.8\% ) sit with crossed legs. Regarding type of the shoes worn, $125(80.1 \%)$ were used sandals,22( 14.1) used special diabetic shoes, and 9(5.8) broad round shoes. . Regarding type of the socks worn, $122(78.2 \%)$ were worn cotton socks, 13(8.3) wool socks, 15(9.6) Nylon socks,6 (3.8) diabetics socks. As shown in (Table 10). 
Table 10. Shows the practice of the study group towards diabetic foot care $(\mathrm{n}=156)$

\begin{tabular}{|c|c|c|}
\hline & $\mathbf{N}$ & $\%$ \\
\hline \multicolumn{3}{|l|}{ Self-feet examination: } \\
\hline Everyday & 134 & 85.9 \\
\hline 2 - 6 times/week & 3 & 1.9 \\
\hline When have problem & 7 & 4.5 \\
\hline No & 12 & 7.7 \\
\hline Patients who wash feet everyday & 152 & 97.4 \\
\hline Patients who dry between toes & 37 & 23.7 \\
\hline Patients who use moisturizing cream & 47 & 30.1 \\
\hline \multicolumn{3}{|l|}{ Person who cut toenail: } \\
\hline By myself & 126 & 80.8 \\
\hline One of family member & 30 & 19.2 \\
\hline Patients who soak their feet & 10 & 6.4 \\
\hline Patients who tested water temp. before usage & 19 & 12.2 \\
\hline Patients who walk on their bare feet & 3 & 1.9 \\
\hline Patients who wore shoes without sock & 73 & 46.8 \\
\hline Patients who inspect their shoes for foreign objects & 95 & 60.9 \\
\hline Patients who use hot water bottle or heating pads & 0 & 0 \\
\hline Patients who set with crossed legs & 6 & 3.8 \\
\hline Patients who smoking & 20 & 12.8 \\
\hline \multicolumn{3}{|l|}{ Kinds of shoes worn: } \\
\hline Broad round & 9 & 5.8 \\
\hline Sandal & 125 & 80.1 \\
\hline Special diabetic shoes & 22 & 14.1 \\
\hline \multicolumn{3}{|l|}{ Kinds of socks worn: } \\
\hline Cotton & 122 & 78.2 \\
\hline Wool & 13 & 8.3 \\
\hline Nylons & 15 & 9.6 \\
\hline Diabetic socks & 6 & 3.8 \\
\hline
\end{tabular}

Regarding patients practice about foot care $97(62.2 \%)$ had moderate practice, $34(21.8 \%)$ had bad practice and 25 $(15 \%)$ had good practice as shown in (table 11$)$.

Table 11. The practice about foot care levels distribution of the study group $(\mathrm{n}=156)$

\begin{tabular}{|c|c|c|}
\hline & $\mathrm{N}$ & $\%$ \\
\hline Bad Practice & 34 & 21.8 \\
\hline Moderate Practice & 97 & 62.2 \\
\hline Good Practice & 25 & 16.0 \\
\hline
\end{tabular}

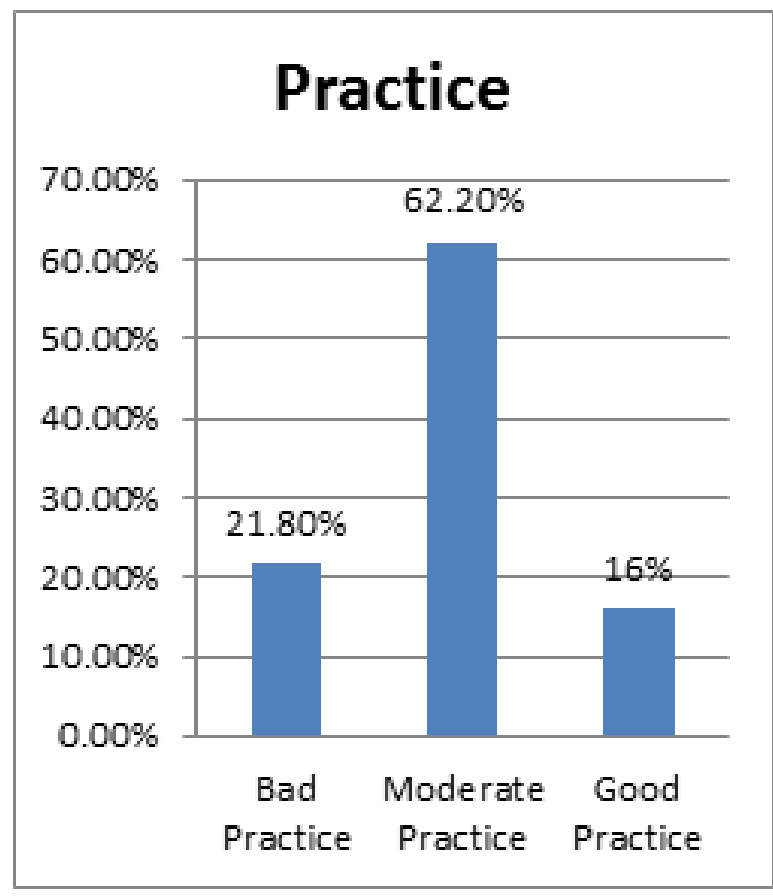

Figure 6. The practice about foot care in the study group $(n=156)$

\section{Relationship between Foot Care and Foot Problems}

Among the 12 patients who had foot ulcers $9(75 \%)$ of them had bad knowledge while the remaining $3(25 \%)$ had good knowledge P. value $=0,003$. Among the 6 patients who had leg sore or cut $2(33,3)$ of them had bad knowledge while the other 4 (66.7\%) had good knowledge P. value $=0.001$. All the 6 patients who are having foot ulcers, blisters or sore had good knowledge P. value $=$ 0.001 , and all the 3 patients who are having discharge or blood in their socks, had good knowledge P.value $=0.001$. Among the 9 Patients who have feet calluses, 6 (66.7\%) had bad knowledge while remaining 3(33.3\%) had good knowledge $\mathrm{P}$. value $=0.001$. Among the 88 patients who have feet numbness, tingling and needles sensation or itching, 28 (31.8\%) had bad knowledge, 3(3.4\%) had average knowledge ,and the remaining 57 (64.8\%) had good knowledge, $\mathrm{P}$. value $=0.055$. Among the 66 patients have tightness, pain or cramps in their feet $25(37.9 \%)$ of them had bad knowledge, 3(4.5\%) had moderate knowledge and the other $38(57,6 \%)$ had good knowledge, P. value $=0.076$. All the 7 patients who have amputations had bad knowledge $(100 \%)$, P. value $=0.001$. as shown in table 12. 
Table 12. show the Relationship between knowledge and foot problems.

\begin{tabular}{|c|c|c|c|c|}
\hline & \multicolumn{3}{|c|}{ Knowledge } & P.value \\
\cline { 2 - 5 } & Bad & Moderate & Good & \\
\hline $\begin{array}{c}\text { Patients had foot } \\
\text { ulcers }\end{array}$ & $9(75 \%)$ & $0(0 \%)$ & $3(25 \%)$ & 0.003 \\
\hline $\begin{array}{c}\text { Patients had leg } \\
\text { sore or cut took } 2 \\
\text { weeks to heal }\end{array}$ & $\begin{array}{c}2 \\
(33.3 \%)\end{array}$ & $0(0 \%)$ & $\begin{array}{c}4 \\
(66.7 \%)\end{array}$ & 0.001 \\
\hline $\begin{array}{c}\text { Patients have } \\
\text { ulcers, blisters or } \\
\text { sore in their feet }\end{array}$ & $0(0 \%)$ & $0(0 \%)$ & $\begin{array}{c}6 \\
(100 \%)\end{array}$ & 0.001 \\
\hline $\begin{array}{c}\text { Patients have } \\
\text { discharge or blood } \\
\text { in their socks }\end{array}$ & $0(0 \%)$ & $0(0 \%)$ & $\begin{array}{c}3 \\
(100 \%)\end{array}$ & 0.001 \\
\hline $\begin{array}{c}\text { Patients have feet } \\
\text { calluses }\end{array}$ & $\begin{array}{c}6 \\
(66.7 \%)\end{array}$ & $0(0 \%)$ & $\begin{array}{c}3 \\
(33.3 \%)\end{array}$ & 0.001 \\
\hline $\begin{array}{c}\text { Patients have feet } \\
\text { numbness, } \\
\text { tingling and } \\
\text { needles sensation } \\
\text { or itching }\end{array}$ & $\begin{array}{c}28 \\
(31.8 \%)\end{array}$ & $3(3.4 \%)$ & $\begin{array}{c}57 \\
(64.8 \%)\end{array}$ & 0.055 \\
\hline $\begin{array}{c}\text { Patients have } \\
\text { tightness, pain or } \\
\text { cramps in their } \\
\text { feet }\end{array}$ & $\begin{array}{c}25 \\
(37.9 \%)\end{array}$ & $3(4.5 \%)$ & $\begin{array}{c}38 \\
(57.6 \%)\end{array}$ & 0.076 \\
\hline $\begin{array}{c}\text { Amputation } \\
(100 \%)\end{array}$ & $0(0 \%)$ & $0(0 \%)$ & 0.001 \\
\hline
\end{tabular}

All the 12 patients who had foot ulcers had bad attitude $(100 \%) \mathrm{P}$. value $=0,001$. All the 6 patients who had leg sore or cut had bad attitude $(100 \%) \mathrm{P}$. value $=0,001$. All the 6 patients who are having foot ulcers, blisters or sore had bad attitude $(100 \%) \mathrm{P}$. value $=0,001$. and all the 3 patients who are having discharge or blood in their socks, had bad attitude $(100 \%) \mathrm{P}$. value $=0,001$. Among the 9 Patients who have feet calluses, $6(66.7 \%)$ had bad attitude while the remaining $3(33.3 \%)$ had moderate attitude $P$. value $=0.002$. Among the 88 patients who have feet numbness, tingling and needles sensation or itching, $67(76,1 \%)$ had bad attitude, $15(17 \%)$ had moderate attitude , and the remaining $6(6,9 \%)$ had good attitude, P.value $=0.045$.Among the 66 patients have tightness, pain or cramps in their feet 48 $(72.7 \%)$ of them had bad attitude, $12(18,2 \%)$ had moderate knowledge, and the other $6(9.1 \%)$ had good attitude, P.value $=0.023$. All the 7 patients who have amputations had bad attitude $(100 \%)$, P.value $=0.001$. as shown in table (13).

Among the 12 patients who had foot ulcers $6(50 \%)$ of them had bad practice, $3(25 \%)$ had moderate practice, while the remaining $3(25 \%)$ had good practice P. value $=0,0036$. Among the 6 patients who had leg sore or cut 3 $(50 \%)$ of them had moderate practice while the other 3 $(50 \%)$ had good practice, P.value 0,60 . Among the 6 patients who are having foot ulcers, blisters or sore, $3(50 \%)$ had bad practice and $3(50 \%)$ had moderate practice, P.value 0.65 . All the 3 patients who are having discharge or blood in their socks, had bad practice, P.value 0,00 . Among the 9 Patients who have feet calluses,5 (55.6\%) had bad practice while remaining $4(44.4 \%)$ had moderate practice,P.value 0.78 . Among the 88 patients who have feet numbness, tingling and needles sensation or itching,50 $(56.8 \%)$ had bad practice, $22(25 \%)$ had moderate practice ,and the remaining 16 (18.2\%) had good practice, P. value $=0.03$. Among the 66 patients have tightness, pain or cramps in their feet $41(62,1 \%)$ of them had bad practice, $13(19.7 \%)$ had moderate practice, and the other $12(18.2 \%)$ had good practice, $P$. value $=0.038$. Among the 7 patients who have amputations, $5(71,4 \%)$ had bad practice, while the remaining $2(28.6 \%)$ had moderate practice , P. value $=$ 001. As shown in table (14).

Table 13. Relationship between the attitude and foot problems.

\begin{tabular}{|c|c|c|c|c|}
\hline & \multicolumn{3}{|c|}{ Attitude } & \multirow{2}{*}{$\begin{array}{c}\text { P. } \\
\text { value }\end{array}$} \\
\hline & Bad & Moderate & Good & \\
\hline $\begin{array}{l}\text { Patients had foot } \\
\text { ulcers }\end{array}$ & $\begin{array}{c}12 \\
(100 \%)\end{array}$ & $0(0 \%)$ & $0(0 \%)$ & 0.001 \\
\hline $\begin{array}{c}\text { Patients had leg sore } \\
\text { or cut took } 2 \text { weeks to } \\
\text { heal }\end{array}$ & $\begin{array}{c}6 \\
(100 \%)\end{array}$ & $0(0 \%)$ & $0(0 \%)$ & 0.001 \\
\hline $\begin{array}{l}\text { Patients have ulcers, } \\
\text { blisters or sore in } \\
\text { their feet }\end{array}$ & $6(0 \%)$ & $0(0 \%)$ & $0(0 \%)$ & 0.001 \\
\hline $\begin{array}{c}\text { Patients have } \\
\text { discharge or blood in } \\
\text { their socks }\end{array}$ & $\begin{array}{c}3 \\
(100 \%)\end{array}$ & $0(0 \%)$ & $0(0 \%)$ & 0.001 \\
\hline $\begin{array}{c}\text { Patients have feet } \\
\text { calluses }\end{array}$ & $\begin{array}{c}6 \\
(66.7 \%) \\
\end{array}$ & $3(33.3 \%)$ & $0(0 \%)$ & 0.002 \\
\hline $\begin{array}{c}\text { Patients have feet } \\
\text { numbness, tingling } \\
\text { and needles sensation } \\
\text { or itching }\end{array}$ & $\begin{array}{c}67 \\
(76.1 \%)\end{array}$ & $15(17 \%)$ & $\begin{array}{c}6 \\
(6.9 \%)\end{array}$ & 0.045 \\
\hline $\begin{array}{l}\text { Patients have } \\
\text { tightness, pain or } \\
\text { cramps in their feet }\end{array}$ & $\begin{array}{c}48 \\
(72.7 \%)\end{array}$ & $\begin{array}{c}12 \\
(18.2 \%)\end{array}$ & $\begin{array}{c}6 \\
(9.1 \%)\end{array}$ & 0.023 \\
\hline Amputations & $\begin{array}{c}7 \\
(100 \%)\end{array}$ & $0(0 \%)$ & $0(0 \%)$ & 0.000 \\
\hline
\end{tabular}

Table 14

\begin{tabular}{|c|c|c|c|c|}
\hline & \multicolumn{3}{|c|}{ Practice } & \multirow{2}{*}{$\begin{array}{c}P . \\
\text { value }\end{array}$} \\
\hline & Bad & Moderate & Good & \\
\hline $\begin{array}{l}\text { Patients had foot } \\
\text { ulcers }\end{array}$ & $6(50 \%)$ & $3(25 \%)$ & $3(25 \%)$ & 0.036 \\
\hline $\begin{array}{l}\text { Patients had leg } \\
\text { sore or cut took } 2 \\
\text { weeks to heal } \\
\end{array}$ & $0(0 \%)$ & $3(50 \%)$ & $3(50 \%)$ & 0.60 \\
\hline $\begin{array}{c}\text { Patients have } \\
\text { ulcers, blisters or } \\
\text { sore in their feet }\end{array}$ & $3(50 \%)$ & $3(50 \%)$ & $0(0 \%)$ & 0.65 \\
\hline $\begin{array}{c}\text { Patients have } \\
\text { discharge or blood } \\
\text { in their socks }\end{array}$ & $\begin{array}{c}3 \\
(100 \%)\end{array}$ & $0(0 \%)$ & $0(0 \%)$ & 0.00 \\
\hline $\begin{array}{c}\text { Patients have feet } \\
\text { calluses }\end{array}$ & $\begin{array}{c}5 \\
(55.6 \%) \\
\end{array}$ & $4(44.4 \%)$ & $0(0 \%)$ & 0.78 \\
\hline $\begin{array}{l}\text { Patients have feet } \\
\text { numbness, tingling } \\
\text { and needles } \\
\text { sensation or itching }\end{array}$ & $\begin{array}{c}50 \\
(56.8 \%)\end{array}$ & $22(25 \%)$ & $\begin{array}{c}16 \\
(18.2 \%)\end{array}$ & 0.03 \\
\hline $\begin{array}{c}\text { Patients have } \\
\text { tightness, pain or } \\
\text { cramps in their feet }\end{array}$ & $\begin{array}{c}41 \\
(62.1 \%)\end{array}$ & $\begin{array}{c}13 \\
(19.7 \%)\end{array}$ & $\begin{array}{c}12 \\
(18.2 \%)\end{array}$ & 0.038 \\
\hline Amputations & $\begin{array}{c}5 \\
(71.4 \%) \\
\end{array}$ & $2(28.6 \%)$ & $0(0 \%)$ & 0.001 \\
\hline
\end{tabular}




\section{Discussion}

In this study,a total number of 156 participants with type

2 diabetes were recruited. Although the prevalence of type

2 diabetes is more in men worldwide, $75 \%$ of the participants were females, while $25 \%$ were males, this may be explained by the fact that more women attend the outpatient clinics than do men. $50 \%$ of the patients' ages

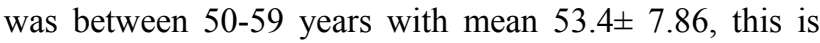
consistent with the global figures of people with type 2 diabetes. $12.8 \%$ of the patients were smokers, most of participants in this study $(72.4 \%)$ do not know that smoking reduced blood flow to the feet. $37.8 \%$ of the study population have duration of diabetes $>10$ years, and $51.9 \%$ using insulin. $56.5 \%$ having hypertension as co- morbidity. Among 12 (7.7\%) having foot ulcers $9(75 \%)$ have loss of sensation P.value 0.003 , that means there is high prevalence of peripheral neuropathy (56.4) among patients with foot ulcer, these finding are in agreement with the study done in Dar es Salsaam , Tanzania, $15 \%$ have foot ulcers, with $44 \%$ prevalence of peripheral neuropathy. These finding signify the importance of education about foot care especially for insensate feet to prevent minor trauma, which is a major factor in the developing of foot ulcers. Patients to be educated on the important of glycemic control so as to prevent long term diabetes, especially on older patients and those with longer duration of diabetes since they are more prone to have peripheral neuropathy and other complications.

Tingling, numbness, and needle sensation are the first symptoms of foot problems, these are major symptoms leading to diabetic foot disease in this study, there is high prevalence of tingling numbness, and needle sensation reaching $56.4 \%$, these finding are near to the finding in the study done in Saudi Arabia which reach $72.8 \%$.and they found that there is an inverse association between tingling sensation and spot practice. The tingling sensation decreases by an increase in exercise time because the exercise increases the circulation of the blood, so nerve has good nutrients. In my study only $25.6 \%$ of the patients were doing exercise, this might contribute to the high prevalence of peripheral neuropathy in this study. $42.3 \%$ of the participants in this study were found to suffer from Tightness, pain or cramps in the leg.

It is widely accepted fact that foot care knowledge is important in preventing diabetic foot ulcers.

Regarding knowledge about foot care in this study 56.4\% of the patients have good knowledge especially they know that loss of sensation can lead to feet ulcer, reduction of blood can lead to feet ulcer, also they knows that infection of feet may developed to gangrene, these results were consistent with the result done in Saudi Arabia by Yahya M.Solan, and et al about Diabetic foot care and knowledge, they found that $53.6 \%$ of the patients had good foot care knowledge . In the study conducted in secondary care Rural Hospital in Southern India about foot care knowledge and practice, they found that $75 \%$ of the patients had good knowledge. These result were in-comparable with the result in the study done in Dar es Salaam, Tanzania - it reported that more than $50 \%$ of the patient had never received information regarding foot care, it is also against the results in the study carried in Sudan in Jabir Abu- alaiz diabetic centre, it revealed that most of the cases had poor knowledge about foot care.

Regarding Attitude about foot care in this study $70.5 \%$ of the patients had bad attitude, only $25.6 \%$ had given foot care information, $14.1 \%$ reads handout on foot care, $56.4 \%$ know the right way of nails trimming (cutting straight through).

In this study regarding foot care practice $21.8 \%$ had bad practice, $16 \%$ had good practice, $62.2 \%$ had moderate practice. Practice is generally inadequate since $23.7 \%$ dry between toes, $30.1 \%$ used moistening cream, $12.2 \%$ tested water temperature before washing, $80.1 \%$ wearing sandal, $46.8 \%$ wore shoes without sock.. The inadequate practice of foot care in this study may be attributed to the inadequate knowledge, and bad attitude of foot care among the participants.

Regarding the relationship between knowledge about diabetic foot care and diabetic foot problems, there is association between diabetic foot ulcer and poor knowledge in this study as $75 \%$ of the patients who had ulcers had bad knowledge, $\mathrm{P}$ value 0.003 .This result is comparable to the study conducted in Jabir A bu- alaiz diabetic centre in Khartoum, Sudan 2014 by Mohamed Maali Gumaa, they found that the level of foot care knowledge proved to have significant contribution to developing diabetic foot ulcer, and it is one of the major causes of diabetic foot ulcer. There is also association between DFU and bad attitude and practice as all of them $(100 \%)$ had bad attitude, and $50 \%$ of them had bad practice, $P$,values 0.000 and 0.036 respectively .These findings are in agreement with cohort study done by GopiChellan, et al about foot care practice- The Key to prevent diabetic foot ulcers in India 2012, they found that there is inverse relationship between DFU and foot care knowledge and practice

There is association between calluses and bad knowledge and attitude as $66.7 \%$ of patients with calluses had bad knowledge, P.value 0.02 and bad attitude as $66.7 \%$ had bad attitude, P.value(0.001).There is no association between calluses and bad practice as $55.6 \%$ had bad practice, P.value 0.78 .

Again there is strong association between toe amputation and poor knowledge and attitude as $100 \%$ of the patients who had toe amputation had bad knowledge and bad attitude and $71.4 \%$ of them had bad practice, $\mathrm{P}$ value 0.000 and 0.001 respectively.

Regarding peripheral neuropathy symptoms, there is no association between PN symptoms and bad knowledge as $64.8 \%$ of the patients who had numbness, tingling and needle sensation, had good knowledge, value 0.55 .But 
there is association between PN and bad attitude and practice as $76.1 \%$ had bad attitude $P$ value 0.045 and $71.4 \%$ had bad practice $\mathrm{P}$ value 0.001 .

Regarding peripheral arterial disease symptoms, again there is no association between PAD symptoms and bad knowledge as $57.6 \%$ of the patients who had tightness, pain or cramps, had good knowledge .P. Value 0.76. But there is association between PAD symptoms and bad attitude and practice as $72.7 \%$ had bad attitude, $P$ value 0.023 and $62.1 \%$ had bad practice $P$ value 0.038 .

In Conclusion the study finding there were high prevalence of symptoms of both peripheral neuropathy and peripheral arterial disease, so urgent educational intervention should be implemented to delay and prevent the development of diabetic foot diseases.

The majority of the patients attending the diabetic clinic had inadequate knowledge, bad attitude, moderate practice of foot care, hence a multidisciplinary effort to raise the awareness about foot care should be emphasized.

An inverse relationship between diabetic foot ulcer and foot care knowledge as well as practice was observed, based on this, diabetic patients must be educated and motivated on proper foot care practices for preventing diabetic foot ulcers.

\section{REFERENCES}

[1] Leung P. diabetic Foot ulcers-A comprehensive review. surgeon. 2007;5(4):219-231.http://dx.doi.org/10.1016/s147 $9.666 \times(07) 80007-2$

[2] Boulton A, Vilei KyteL, Rangnarson-TennvallG, Apelquist J. Theglobal burden of diabetic foot disease . Lancet.2005; 336:1724. 10.1016/s0140-6736(5)67698-2

[3] Frykberg R, Armstrong D, Giurini J, et al. Diabetic foot disorders: A clinical practice guideline. Foot Ankle surg..2000; 39(5): S1-S66.

[4] Yavuz D .Tuglular S, Ersoz H, Alutun A, Archer A, Akalin A . Awareness of diabetic foot disease in agroup of Turkish and English patients with type 2 Diabetes Mellitus: Assessment of The states and the efficacy of diabetic foot education programs. Turkish J Endocrinal Metab1999;2:65-70

[5] Dunber GL, Hellenberg DA ,Levitt NS .Diabetes Mellitus and non-traumatic lower extremity amputations in Four public sector hospital in cape Town, South Africa. dunny 2009 and 2010. SAfrMed J. 2015;105(12): 1053-105610-7196/SAmj.2015-V105i12.9276

[6] Goody C, Muchison R ,DhateriyaK .An Analysis of clinical activity, admission, rates, length of hospital stay in the United Kindom. Diabetic Foot and Ankle. 2013;4:21757

[7] Gordois A, Scuffham P, ShearerA, Oglesby A, Tobian JA .The health care costs of diabetic peripheral neuropathy in the US. Diabetes Care,2002,Vol.26(pg.1790-5)

[8] Reiber GE, Lipsky BA, Gibbons GW. The burden of diabetic foot ulcers, Am J Sur .1998 Vol 176 Suppl 2 A (pg. 5-10)

[9] Andrew J, Gunne R, Jan A. The global burden of diabetes foot disease. Lancet. 2005; 366: 1719-24.

[10] Basu S, Haldey J, Tan RM, William J, Shearman CP. Is there enough information about foot care among patients with? Int J Low Extrem Wounds. 2004; 64-8.

[11] Wikblad K, Smide B, B ergstrom AKessi J, Mugusi F. Outcome of clinical foot examination in relation to self-mpreceived health and glycemic control in agroup of urban Tanzanian diabetic patients. Diabetes Res Clin Pract. 1997; 37: 185-92.

[12] Alkhier Ahmed A, Alsharief A, Alsharief E. The diabetic foot in the arab world. The Journal of Diabetic Foot Compl. ications. 2011; Volume 3, Issue 3 No. 3:p.55-61.

[13] Balla SA, Ahmed HA, Alhassan SF. Factors associated with diabetic septic foot among patients attending the diabetic septic foot unit in the military hospital Khartoum state, Sudan .Saudi Journal of Medicine \&Medical Sci.

[14] Kelly Cheer; et al. specialist trainee 4 in diabetes and endocrinology 1. BMJ 2009;339, 10.1136bmj,b4905

[15] MatriccianiL, Jones S- Who care about foot care? Barriers and enables of foot self - care practices among non institutionalized older adults diagnosed with diabetes: an integrative review. Diabetes Educ 2015 Feb; 41 (1): $106-$ 17.

[16] Lavery LA, Wunerlich RP, Tredwell JL. Diseases management for the diabetic foot: effectiveness of adiabatic foot prevention program to reduce amputations and hospitalizations .Diabetes Research and clinical Practice 2005; 70:31- 7 .

[17] Kruger S, Guthrie D, Foot care knowledge retention and self -care practices. Diabetes Edu 1992; 18. 489 - 90.

[18] American Diabetes Association .Diabetes care 2004 Jan; 27 (suppl) 1

[19] Mcinnes AD. Diabetic foot diseases in the United Kingdom: about time to put bfeet first.Foot Ankle Res. 2012; $5: 26$. Resolution 66/2. Political Declaration of the High-level Meeting of the General Assembly on the Prevention and Control of Non communicable Diseases. In Sixty- sixth session of the United Nations General Assembly. New York: United Nations; 2011.

[20] WHO Mortality Database [online database]. Geneva: World Organization. Int/healthinfo/statistics/mortality/causeofdeat h- query/, accessed12 January2016).

[21] NCD Risk Factor Collaboration (NCD-RisC), worldwide trends in diabetes since 1980: apooled analysis of 751 populatiom- based studies with $4 * 4$ million participants, Lancet 2016; published onlineApril 7. /10.1016/S0140-6736 (16)00618-8.

[22] N- Cho, D.Whiting , N. Forouhi et al ., IDF Diabetes Atlas, $7^{\text {th }}$ edition, 2015

[23] Y. Zheng, T. Y.Wong, C.Y.-L . Cheung et al ,." Influence of diabetes and diabetic retinopathy on the performance of heildberg retina tomography11 for diagnosis of glaucoma", Investigative ophthalmology and Visual Science, Vol.51, 
no.11,PP.5519-5524, 2010.

[24] Clinical Practice Guideline on management of patients with diabetes and chronic Kidney disease stage $3 \mathrm{~b}$ or higher (e GFR $<45 \mathrm{ml} / \mathrm{min}$ ).Nephrol Dial Transplant 2015; 30 (Suppl 2) : ii1-ii142.

[25] Centres For Disease Control and Prevention, National diabetes fact sheet: national estimates and general information on diabetes and prediabetes in the United States, Atlanta, Ga, USA,2011.

[26] Rathur HM, Boulton, AJ. Thediabetic foot. Clin Dermatol.2007;25: 109-120.

[27] UK Prospective DiabetesStudy (UKPDS) Group. Intensive bloo d-glucose control with sulphonylureas or insulin compared with comventional treatment and risk ofcomplictions in patients with type 2 diabetes (UKPDS33) Lancet, 1998;352:837-853.

[28] Katsilambros N. Who is the patient at risk for foot ulceration? In: Katsilambros N, Dounis E, Tsapogas P and Tentolouris N Atlas of the diabetic foot, editors. Chichester; Hoboken, N J: Wiley; 2003. PP.1 -21.

[29] Reiber GE, Vileikyte L, Boyko EJ, del Aguila M, Smith DG, Lavery LA, Boulton AJ. Causal pathways for incident Lower-extremity ulcers in patients with diabetes from two settings. Diabetes Care. 1999;22: 157-162.

[30] Young MJ, Boulton AJ, Macleod AF, Williams DR, Sonksen PH. Amulticentre study of the prevalence of diabetic peripheral neuropathy in the United Kingdom hospital clinic population, Diabetologia, 1993; 36: 150-154.

[31] Boulton AJ, Kirsner RA, Vileikyte L. Clinical practice .Neuropathic diabetic foot ulcers. N Engl J Med. 2004; 351:48-55.

[32] Boyko EJ, Ahroni JH, Stensel V, Forsberg RC, Davignon DR, Smith DG. Aprospective study of risk factors diabetic foot ulcer. The Seattle Diabetic Foot Study. Diabetes Care.1999;22: 1036-1042.

[33] Shaw JE, Boulton A J. The pathogensis of diabetic foot problems: an overview. Diabetes. 1997; 46 Suppl2:S58-S61.

[34] Nabuurs-Franssen MH, Houben A J, Tooke JE,Schaper NC.The effect of polyneuropthy on foot microcirculation in Type2 diabetes. Diabetologia. 2002; 45: 1164-1171.

[35] Dyck PJ. Detection, characterization, and staging of polyneuropathy: assessed in diabetics. Muscle Nerve.1988; 11:21-32.

[36] Dyck PJ, Kratz KM, Lehman KA, Karnes JL, Melton L J,O Brien PC, Litchy Study: design, criteria for types of neuropathy, Selection bias, and reproducibility of neuropathic tests. Neurology. 1991; 41: 799-807.

[37] Valk GD, de Sonnaville JJ, Van Houtum WH,Heine RJ, Van Eijk JT, Bouter LM, Bertelsmann FW.The assessment of diabetic polyneuropathy in daily clinical practice: reproducibility anvalidity of semmes Weinstein monofilaments examination and clinical neurological examination. Muscle Nerve.1997; 20: 116-118.

[38] Mayfield JA, Sugarman HR. The use of the Semmes-Weinstein monofilament and other threshold tests for preventing foot ulceration and amputation in persons with diabetes. J Fam Pract. 2000; 49: S17-S29.

[39] Rith- Najarian SJ, Stolusky T, Gohdes DM, Identifying diabetic patients at high risk for lower-extremity amputation in a primary health care setting. A prospective evaluation of simple screening criteria. Diabetes Care. 1992; 15:1389.

[40] Pham H,Armstrong DG, Harvey C, Harkless LB, Giurini JM, Veves A. Screening techniques to identify people at high risk for diabetic foot ulceration:a prospective multinuclear trial. Diabetes Care.2000;23: 606-611.

[41] Liniger C, AlbeanuA, Bloise D, AssalJP,The tuning fork. Revisited. Diabet Med 1990; 7: 859-864.

[42] Thivolet C, el Farkh J,Petiot A, Simonet C,Tourniaire H.Measuring vibration sensations withgraduated tuning fofk.Simle and reliable means to detect diabetic patients at risk of neuropathic foot ulceration.Diabetes Care. 1990; 13:1077-1080.

[43] Akbari CM, Macsata R, Smith BM, SidawyAN. Overview of the diabetic foot. Semin Vasc Surg. 2003; 16:3-11.

[44] Criqui M (2001) Peripheral arterial disease: epidemiological aspects. Vascular Medicine 6:3-7.

[45] Halperin JL, Evaluation of patients with peripheral vascular disease. Thromb R es. 2002; 106:V303-V311.

[46] Brooks B, Dean, R, Patel S, Wu B, Molyneaux L, Yue DK. TBI or not TBI: that is the question. Is it better to measure toe pressure than ankle pressure in diabetic patients? Diabet Med.2001;18:532.

[47] A. J. M. Boulton, "The pathway to foot ulceration in diabetes, " Medical Clinica of North America, Vol. 97, no.5, pp.775-790, 2013.

[48] L. A. Larvey, N. A.Hunt, J. LaFontaine, C. L. Baxter, A. Ndip, and A. J. M. Boulton, 'Diabetic foot prevention: aneglected opportunity in high -risk patients, Diabetes Care, Vol. 6, no. 4,PP. 329-332, 2012.

[49] Waaijman R, de Haart M, Arts ML, Wever D, Verlouw AJ, Nollet F, BusbbSA. Risk factors for plantar foot ulcer recurrence in neuropathic diabetic patients. Diabetes Care.2014; 28: 574-1697-1705.

[50] McEwen LN, Ylitalo KR, Herman WH, Wrobel JS. Prevalence and risk factors diabetes- related foot complications in Translating Research Into action for Diabetes (TRIAD) J Diabetes complications 2013; 27: 588-592.

[51] Snyder RJ, Hanft JR. Diabetic foot ulcers - effects on QOL. Costs. And mortality and the role of standard wound care and advanced- care therapies. Ostomy Wound Mange.2009;55:28-38

[52] Vileikyte L, Diabetic foot ulcers: aquality of life issue. Diabetes Metab Res Rev. 2001; 17: 246-249.

[53] Boulton A J, Vileikyte L, Ragnarson - T ennvall G,Apelqvist The global burden of diabetic foot disease. Lancet.2005; 366: 1719-1724.

[54] Wagner FW. The dysvascukar foot: a system of diagnosis and treatment. Foot and Ankle 1981; 2:64-12249Armstrong DG, Larvey LA Harkless LB. Validation of a diabetic wound classification system : the contribution of 
depth, infection and

[55] Armstrong DG, Larvey LA \& Harkless LB. Validation of adiabetic wound classification system: the contribution of depth, infection and vascular disease to the risk of amputation. Diabetes Care 1998; 21:855-859.

[56] Leone S, Pascale R, Vitale M, Esposito S. [Epidemiology of diabetic foot] Infez Med. 2012; 20 Suppl 1:8-13.

[57] Richard JL, Schuldiner S. [Epidemiology of diabetic problem] Rev Med Interne. 2008; 29 Suppl 2: S222-s230.

[58] S. Pscherer, F,-W. Dippel, S, Lauterbach, and K. Kostev, "amputation rate and risk factors in type 2 patients with diabetic foot syndrome under real- life conditions in Germany," Primary Care Diabetes, Vol. 6, no. 3, PP.241-246, 2012.

[59] M.Weck, T. Slesaczeck, H. Paetzold et ak,. " Structured health care for subjects with diabetic foot ulcers results in areduction of major amputation rates,"Cardiovascular Diabetelogy, Vol 12, article 45, 2013. J.

[60] Van Olmen, K.G .Marie, D.Christin et al., “ Content, participants and outcomes of three diabetes care programmes in three low and middle income countries" Primary Care Diabetes, 2014.

[61] M. A.Quddus and M. L. Uddin, "'Evaluation of foot ulcers in diabetic patients" , Mymensingh Medical Journal, Vol.22, no. 3, pp. 527-532, 2013.

[62] J. S.Markowitz, E. M. Gutterman, G. Magee, and D. J...Margolis, "Risk of amputation in patients with diabetic foot ulcer: acclaims- based study." Wound Repair and Regeneration, Vol14, no. 1, pp11-17, 2006.

[63] T. Carlson and J. F. Reed 111, "A case - control study of the risk factors for toe amputation in adiabatic population ,'The international Journal of Lower Extremity Wounds, Vol.2, no. 1,pp. 19-21, 2003.

[64] N. Chaturvedi, K. Stevena, J. H.Fuller, E. T Lee, and M. Lu, Risk Factorss, ethnic differences and mortality associated with Lower- extremity gangrene and amputation in diabetes. The WHO multinational study of vascular disease in diabetes, " Diabetological, Vol. 44, supplement 2, pp. S65S71, 2001 